\title{
Unravelling how in vitro capacitation alters ram sperm chromatin before and after cryopreservation
}

Patricia Peris-Frau, Manuel Alvarez-Rodriguez, Alicia Martin-Maestro, Maria IniestaCuerda, Irene Sanchez-Ajofrin, Daniela Alejandra Medina-Chavez, Jose Julian Garde, Margarita Villar, Heriberto Rodriguez-Martinez and Ana Josefa Soler

The self-archived postprint version of this journal article is available at Linköping University Institutional Repository (DiVA):

http://urn.kb.se/resolve?urn=urn:nbn:se:liu:diva-170535

N.B.: When citing this work, cite the original publication.

Peris-Frau, P., Alvarez-Rodriguez, M., Martin-Maestro, A., Iniesta-Cuerda, M., Sanchez-Ajofrin, I., Medina-Chavez, D. A., Garde, J. J., Villar, M., Rodriguez-Martinez, H., Soler, A. J., (2020),

Unravelling how in vitro capacitation alters ram sperm chromatin before and after cryopreservation, Andrology. https://doi.org/10.1111/andr.12900

Original publication available at:

https://doi.org/10.1111/andr.12900

Copyright: Wiley

http://eu.wiley.com/WileyCDA/ 


\section{ANDROLOGY}

\section{Unraveling how in vitro capacitation alters ram sperm chromatin before and after cryopreservation}

\begin{tabular}{|c|c|}
\hline Journal: & Andrology \\
\hline Manuscript ID & ANDR-2020-0031.R1 \\
\hline Manuscript Type: & Original Article \\
\hline $\begin{array}{r}\text { Date Submitted by the } \\
\text { Author: }\end{array}$ & $n / a$ \\
\hline Complete List of Authors: & $\begin{array}{l}\text { Peris-Frau, Patricia; Instituto de Investigacion en Recursos Cinegeticos } \\
\text { Alvarez-Rodriguez, Manuel; Linkopings universitet, IKE, BKH, Obstetrics } \\
\text { and Gyncecology; Universitat Autonoma de Barcelona, Department of } \\
\text { Health and Animal Anatomy } \\
\text { Martin-Maestro, Alicia; Instituto de Investigacion en Recursos } \\
\text { Cinegeticos } \\
\text { Iniesta-Cuerda, María; Instituto de Investigacion en Recursos } \\
\text { Cinegeticos } \\
\text { Sánchez-Ajofrín, Irene; Instituto de Investigacion en Recursos } \\
\text { Cinegeticos } \\
\text { Medina-Chavez, Daniela Alejandra; Instituto de Investigacion en } \\
\text { Recursos Cinegeticos } \\
\text { Garde, J } \\
\text { Villar, Margarita; Instituto de Investigacion en Recursos Cinegeticos } \\
\text { Rodriguez, Heriberto; Linkopings universitet, IKE, BKH, Obstetrics and } \\
\text { Gyncecology } \\
\text { Soler, Ana Josefa; Instituto de Investigacion en Recursos Cinegeticos }\end{array}$ \\
\hline Major Area: & Basic Science \\
\hline Clinical: & Assisted Reproduction \\
\hline Basic Science: & Cell Biology \\
\hline Specific Topics: & Spermatozoa \\
\hline
\end{tabular}


1 Unraveling how in vitro capacitation alters ram sperm chromatin

2 before and after cryopreservation

3

4 Patricia Peris-Frau ${ }^{1,2}$, Manuel Álvarez-Rodríguez ${ }^{2}$, Alicia Martín-Maestro ${ }^{1}$, María

5 Iniesta-Cuerda ${ }^{1}$, Irene Sánchez-Ajofrín ${ }^{1}$, Daniela AlejandraMedina-Chávez ${ }^{1}$, José Julián

6 Garde $^{1}$, Margarita Villar ${ }^{1,3}$, Heriberto Rodriguez-Martinez ${ }^{2}$, Ana Josefa Soler ${ }^{1 *}$

7

$8 \quad{ }^{1}$ SaBio IREC (CSIC -UCLM-JCCM), ETSIAM. Albacete, Spain.

$9 \quad{ }^{2}$ Department of Biomedical and Clinical Sciences (BKV), BHK/Obstetrics \&

10 Gynaecology, Linköping University, Linköping, Sweden

$11{ }^{3}$ Biochemistry Section, Faculty of Science and Chemical Technologies, and Regional

12 Centre for Biomedical Research (CRIB)

13 Running title: Chromatin changes during capacitation in ram spermatozoa

14

15 Keywords: chromatin condensation, DNA methylation, cryopreservation, capacitation, 16 ram spermatozoa

17

* Corresponding Author: AnaJosefa.Soler@uclm.es

ETSIAM. UCLM, Campus Universitario s/n. 020071. Albacete (Spain)

20 


\section{ABSTRACT}

27 Background: Sperm chromatin structure provides valuable information for the

28

prediction of male fertility and can be altered during different procedures. Previous studies have shown that sperm chromatin condensation decreased during in vitro capacitation. Moreover, cryopreservation can affect sperm DNA integrity and chromatin compaction.

Objectives: This study aimed to investigate dynamic modifications produced in the chromatin structure of ram spermatozoa during in vitro capacitation before and after cryopreservation.

Materials and methods: Chromatin decondensation $(\mathrm{AB}+)$, DNA methylation, DNA fragmentation index (\%DFI) and high DNA stainability (HDS) were evaluated in fresh and frozen-thawed ram spermatozoa incubated under capacitating (CAP) conditions at $1,5,15,30,60,120,180$ and $240 \mathrm{~min}$ and under non-capacitating (NC) conditions at 0 , 15 and $240 \mathrm{~min}$.

Results: Incubation in NC conditions did not induce significant changes in chromatin condensation $(\mathrm{P}>0.05 ; \mathrm{AB}+$ and $\mathrm{HDS})$. However, incubation of fresh and cryopreserved ram spermatozoa under CAP conditions significantly increased chromatin decondensation $(\mathrm{P}<0.05)$, reaching the highest percentage of $\mathrm{AB}+$ and HDS from 180 to $240 \mathrm{~min}$ in fresh samples and from 5 to $30 \mathrm{~min}$ in cryopreserved samples. Both variables (HDS and $\mathrm{AB}+$ ) were positively correlated with tyrosine phosphorylation, total motility, progressive motility, curvilinear velocity, and amplitude of lateral head displacement, as well as between them under CAP conditions in fresh and cryopreserved spermatozoa. DNA methylation significantly increased in cryopreserved spermatozoa $(\mathrm{P}<0.05)$, but only after extended incubation under CAP 

conditions (60-240 min), while the \%DFI, albeit higher in cryopreserved samples, remained constant under CAP and NC conditions in both types of sample $(\mathrm{P}>0.05)$.

52 Discussion and conclusions: Our results suggest that sperm chromatin condensation decreased progressively during in vitro capacitation of ram spermatozoa, while sperm DNA integrity remained intact. Such changes in chromatin condensation appeared faster after sperm cryopreservation.

\section{INTRODUCTION}

Recent discoveries have shown that the contribution of spermatozoa to offspring

59 includes, besides the paternal genome, a complex set of RNAs, proteins and epigenetic 60 marks such as DNA methylation and histone post-translational modifications. ${ }^{1-3}$

61 Moreover, the small nucleohistone fraction retained in mature spermatozoa, which is transmitted to the progeny, is associated with specific loci involved in embryogenesis. ${ }^{4-}$

${ }^{6}$ Consequently, any significant perturbation in the sperm chromatin structure could lead to infertility, fertilization failure, spontaneous abortion, abnormal embryo development or even cause different disorders in the offspring. ${ }^{7-11}$

Mature spermatozoa have a highly compacted chromatin to protect paternal

67 genetic and epigenetic inheritance during the spermatozoon's journey to the oocyte. Many histones are replaced by protamines during spermatogenesis, which increase the packaging and condensation of sperm chromatin. ${ }^{12}$ This repackaging process finally 70 ends in the formation of disulphide bonds between protamines during epididymal 71 maturation. ${ }^{13}$

Several studies have shown that abnormalities in sperm chromatin condensation

73 may affect the fertilizing potential of spermatozoa. ${ }^{14-16}$ Furthermore, sperm chromatin must be completely decondensed at the appropriate velocity and time in the fertilization 
75 process for successful formation of the male pronucleus and zygote. ${ }^{17}$ Recently, the

76 ability of human spermatozoa to decondense in vitro has been related with embryo

77 quality, obtaining better embryo quality when sperm chromatin decondenses faster. ${ }^{18}$

78 This finding highlights the relevance of optimal chromatin decondensation for proper

79 embryo development.

80 Some authors have investigated whether the acquisition of sperm fertilizing

81 ability through the physiological process known as capacitation ${ }^{19,20}$ might prepare the

82 sperm chromatin for optimal remodelling after oocyte penetration. In boar spermatozoa,

83 a reduction in disulphide bonds between protamines was observed under capacitating

84 conditions, ${ }^{21}$ while in bull and human spermatozoa, the degree of chromatin

85 condensation decreased during in vitro capacitation without affecting DNA integrity. ${ }^{22-}$

8624 Such changes in nuclear compaction could facilitate the events surrounding and

87 following fertilization, as has been suggested by De Lamirande et al. ${ }^{22}$ In line with these

88 findings, Pérez-Cerezales et al. ${ }^{25}$ demonstrated that a specific subpopulation of

89 capacitated spermatozoa was selected by in vitro thermotaxis in humans and mice.

90 These selected spermatozoa showed less condensed chromatin and greater DNA

91 integrity than unselected spermatozoa, yielding better cleavage and pregnancy rates

92 when used for intracytoplasmic sperm injection (ICSI) in mice. In ram spermatozoa,

93 studies on the effect of capacitation on the chromatin structure are still required.

94 On the other hand, cryopreservation is another process that may affect the

95 structure of sperm chromatin and at the same time accelerate sperm capacitation. ${ }^{26-32}$

96 Some studies revealed that cryopreservation reduced disulphide bonds between nuclear

97 proteins in boar spermatozoa, ${ }^{33}$ increased sperm DNA methylation in stallion ${ }^{34}$ and

98 modified the chromatin stability of diverse species due to membrane damage. ${ }^{35}$ 
99 However, to the best of our knowledge, there is a lack of studies regarding the effect of

100

101 cryopreservation and subsequent in vitro capacitation on sperm chromatin structure.

In the present study, sperm chromatin condensation, DNA integrity and DNA methylation were evaluated in fresh and cryopreserved ram spermatozoa during the time course of in vitro capacitation to verify whether capacitation induces chromatin changes in ram spermatozoa and how cryopreservation may affect these nuclear changes associated with sperm capacitation. We hypothesised that partial chromatin decondensation might take place during capacitation to ensure proper sperm chromatin remodelling after oocyte penetration, occurring in cryopreserved ram spermatozoa faster than in fresh spermatozoa and without inducing DNA damage.

\section{MATERIALS AND METHODS}

\section{Semen collection and cryopreservation}

Semen was collected at one-week intervals by artificial vagina from four mature Manchega rams (4-5 years old) housed at the UCLM experimental farm. The procedure was carried out by the UCLM Reproduction Biology Group which is officially authorized for collecting and storing sheep semen (ES07RS02OC), following RD 841/2011.The experiment was repeated three times using one pool of four ejaculates each time avoid individual variability. A total of three ejaculates from each ram, with a minimum of $65 \%$ sperm motility and a wave motion value of 3.5 , were used in the study. Sperm concentration ranged from 3,560 to $4,105 \times 10^{6} \mathrm{sperm} / \mathrm{ml}$ and was calculated using a Makler counting chamber and the Sperm Class Analyzer software $\left(\mathrm{SCA}^{\circledR}\right)$ (Microptic, Barcelona, Spain).

Each pool was divided into two fractions, one processed as fresh semen, and the other cryopreserved in straws with Biladyl ${ }^{\circledR}$ (Minitube; Tiefenbach, Germany) and 
124 thawed in a water bath at $37{ }^{\circ} \mathrm{C}$ for $30 \mathrm{~s}$. Both fractions were processed at $30{ }^{\circ} \mathrm{C}$ until 125 the incubation period.

For cryopreservation, semen diluted to $200 \times 10^{6} \mathrm{sperm} / \mathrm{ml}$ in Biladyl ${ }^{\circledR}$ (with $20 \%$ egg yolk and $7 \%$ glycerol) was slowly cooled from $30{ }^{\circ} \mathrm{C}$ (initial temperature) to 5 ${ }^{\circ} \mathrm{C}$ for $2 \mathrm{~h}$ and subsequently equilibrated at $5{ }^{\circ} \mathrm{C}$ for $2 \mathrm{~h}$. Semen samples were then automatically packed into $0.25 \mathrm{ml}$ straws, frozen in a programmable biofreezer (Planer Kyro 10 Series III; Planer PLC, London, United Kingdom) following a freezing curve ( $-20{ }^{\circ} \mathrm{C} / \mathrm{min}$ from $5{ }^{\circ} \mathrm{C}$ to $-100{ }^{\circ} \mathrm{C}$ and $-10{ }^{\circ} \mathrm{C} / \mathrm{min}$ from $-100{ }^{\circ} \mathrm{C}$ to $-140{ }^{\circ} \mathrm{C}$ ) and stored in liquid nitrogen.

\section{Sperm preparation and experimental design}

134 Fresh and frozen-thawed semen were centrifuged through single columns of Percoll $^{\circledR} 45 \%$ (Sigma-Aldrich; Madrid, Spain) (700 x g; $10 \mathrm{~min}$ ) at room temperature $\left(30^{\circ} \mathrm{C}\right)$ to remove seminal plasma, extenders and debris. After centrifugation, sperm

137 pellets were resuspended to a final concentration of $10 \times 10^{6} \mathrm{sperm} / \mathrm{ml}$ in synthetic 138 oviductal fluid (SOF) $)^{36}$ supplemented with $0.1 \%$ of polyvinyl alcohol (PVA) for non139 capacitating conditions (NC) or in SOF supplemented with $2 \%$ of oestrous sheep 140 serum $^{37-39}$ for capacitating conditions (CAP). Then, fresh and cryopreserved 141 spermatozoa were incubated up to $240 \mathrm{~min}$ in NC or CAP medium at $38.5^{\circ} \mathrm{C}$ under $5 \%$ $142 \mathrm{CO}_{2}$. In vitro capacitation of ram spermatozoa was confirmed by assessing the global 143 increase in tyrosine phosphorylated proteins that characterizes this event (described 144 below). ${ }^{40,41}$

145 Chromatin decondensation $(\mathrm{AB}+)$, DNA methylation, DNA fragmentation index $146(\% \mathrm{DFI})$ and high DNA stainability (HDS) were the nuclear variables evaluated in fresh 147 and cryopreserved spermatozoa after 1, 5, 15, 30, 60, 120, 180 and 240 min under CAP 148 conditions and after 0,15 and 240 min under NC conditions. At the same time intervals, 
149 mitochondrial activity, ROS production, apoptosis, protein tyrosine phosphorylation $150(\mathrm{pY})$ and diverse kinematic variables were investigated in fresh and cryopreserved 151 spermatozoa to verify whether these variables were related to the nuclear variables 152 evaluated under CAP and NC conditions, or not.

\section{Aniline blue (AB) staining}

$154 \quad$ Mature spermatozoa have a highly compacted chromatin after the replacement 155 of many histones by protamines during spermatogenesis. Any change in the 156 condensation of chromatin can be detected by aniline blue (AB) due to its ability to 157 selectively stain lysine residues of persisting histones. This cytochemical stain has 158 frequently been used to identify sperm samples from different individuals showing 159 chromatin immaturity or lower chromatin condensation due to abnormal histone 160 retention. However, reorganization of the sperm chromatin structure during 161 physiological events, such as sperm capacitation, could also make histones more 162 accessible to $\mathrm{AB}$, revealing changes in chromatin condensation. ${ }^{22}$ Spermatozoa with a 163 loose chromatin packaging are stained with $\mathrm{AB}$ because of their high histone levels, 164 while spermatozoa with a tight chromatin packaging are not stained with $A B$ because of 165 their low histone levels. ${ }^{42}$ To assess aniline blue staining, air-dried smears $(15 \mu 1$ 166 sperm/sample) obtained at different incubation times were fixed with $3 \%(\mathrm{v} / \mathrm{v})$ 167 glutaraldehyde in PBS ( $\mathrm{pH} 7.2)$ for $30 \mathrm{~min}$. Then, slides were stained with 5\% (v/v)

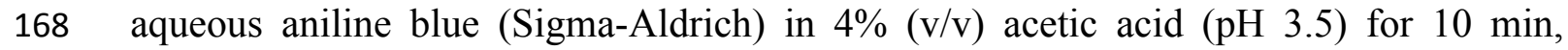
169 washed with water, allowed to dry and mounted with DPX (Sigma-Aldrich). As a 170 positive control for chromatin decondensation, an air-dried smear from spermatozoa 171 obtained at 0 min was incubated with $1 \%(\mathrm{w} / \mathrm{v})$ SDS and $1 \mathrm{mM}$ DTT for $15 \mathrm{~min}$ before 172 following the staining protocol. Using a light microscope (Eclipse 80i; Nikon, Tokyo, 173 Japan), 300 spermatozoa were assessed per sample at 60x magnification. Spermatozoa 
174 with unstained nuclei $(\mathrm{AB}-)$ indicated normal chromatin condensation while those blue

175 stained indicated chromatin decondensation $(\mathrm{AB}+)$ (Figure 1). Results were expressed

176 as the percentage of spermatozoa with $\mathrm{AB}+$ heads.

\section{Sperm chromatin structure assay $\left(\mathbf{S C S A}^{\circledR}\right)$}

178 Changes in chromatin integrity were evaluated by the sperm chromatin structure

179 assay $\left(\mathrm{SCSA}^{\circledR}\right)$.This flow cytometry test measures the susceptibility of sperm DNA to 180 acid-induced denaturation using the metachromatic properties of acridine orange (AO), 181 a dye that emits green fluorescence when bound to intact DNA (double-stranded DNA) and red fluorescence when bound to denatured DNA (single-stranded DNA, obtained after denaturation of DNA at the sites of strand breaks). The metachromatic shift of AO is captured as fluorescence intensity cytogram patterns and then processed to obtain the extent of DNA fragmentation for each spermatozoon. SCSA ${ }^{\circledR}$ was performed following the procedure described by Evenson et al. ${ }^{43}$ Samples taken at different time points of incubation were diluted to $2 \times 10^{6}$ cells $/ \mathrm{ml}$ with TNE buffer and mixed with $400 \mu \mathrm{l}$ of an acid-detergent solution for $30 \mathrm{~s}$. Then, $1.2 \mathrm{ml}$ of $\mathrm{AO}$ was added, and samples were evaluated 2 min later with a Gallios ${ }^{\mathrm{TM}}$ flow cytometer (Beckman Coulter; Bromma, Sweden). AO was excited with a 488nm argon laser. Red fluorescence was detected with FL3 (655SP; 620/30) and green fluorescence with FL1 (550SP; 525BP). FL1 and

FL3 were adjusted to $475 \pm 5$ and $125 \pm 5$, respectively, with a standard sample before running all the sperm samples. A total of 5,000 spermatozoa per sample were evaluated.

194 Flow cytometry data (FCS) were acquired by the Navios software (Beckman Coulter; 195 Bromma, Sweden) and processed by WEASEL v. 3.2 (WEHI; Melbourne, Australia). 196 Further analyses of FCS using R software (package rflowcyt - Bioconductor) were done 197 to obtain the DNA fragmentation index (DFI) in each sample, which is the ratio of red to total fluorescence intensity (red + green), the percentage of spermatozoa with a DFI 
superior to $25 \%(\% \mathrm{DFI})$ and the percentage of spermatozoa with high DNA stainability

(HDS; spermatozoa with green fluorescence intensity above 600 in FL1).

201

202

203

204

205

206

207

208

209

210

211

212

213

214

215

216

217

218

219

220

221

222

223

\section{5-Methylcytosine immunostaining}

Variations in sperm DNA methylation were investigated by immunostaining.

The immunoassay was performed following the procedure described by Benchaib et al. ${ }^{44}$, but with some modifications. Briefly, air-dried smears (15 $\mu 1$ sperm/sample) obtained at different incubation times were fixed with $4 \%(\mathrm{v} / \mathrm{v})$ paraformaldehyde (Sigma-Aldrich) in PBS for $30 \mathrm{~min}$. After washing twice with $0.5 \%(\mathrm{v} / \mathrm{v})$ Tween 20 (Sigma-Aldrich) in PBS (PBS-T), DNA decondensation was carried out by incubation in $1 \mathrm{M}$ Tris-HCl buffer (pH 9.5) supplemented with $25 \mathrm{mM}$ dithiothreitol (DTT) at room temperature (RT) for 20 min. Slides were washed three times with PBS-T and sperm DNA was denatured after 25 min with $6 \mathrm{~N}$ HCL. Slides were then washed three times with PBS-T and incubated at RT in blocking buffer (Odyssey ${ }^{\circledR}$ blocking buffer; LI-COR Biosciences, Lincoln, NE, USA). After $1 \mathrm{~h}$, spermatozoa were incubated with a monoclonal anti-5-methylcytosine antibody (Ab 10805; Abcam, Cambridge, UK) diluted 1:500 in blocking buffer at $4^{\circ} \mathrm{C}$ in a humidified chamber overnight. The slides were then washed in PBS-T and incubated with Alexa fluor488 labelled Goat antimouse IgG (Ab150113; Abcam, dilution 1:500 in blocking buffer) in a humidified chamber for $1 \mathrm{~h}$. Spermatozoa incubated with buffer instead of the primary antibody were used as a negative control. The samples were washed with PBS-T, allowed to dry and mounted with anti-fade solution (Slowfade ${ }^{\circledR}$ Diamond; Life technologies, Linköping, Sweden). From each sample, 300 spermatozoa were analysed with a fluorescence microscope at 100x magnification (Eclipse Ti; Nikon). Spermatozoa showing green fluorescence at their heads were considered methylated (Figure 2) and results were expressed as the percentage of spermatozoa with DNA methylation. 
224

225

226

227

228

229

230

231

232

233

234

235

236

237

238

239

240

241

242

243

244

245

246

247

248

\section{Sperm kinematics}

Diverse kinematic variables, including total motility (TM; \%), progressive motility (PM; \%), curvilinear velocity (VCL; $\mu \mathrm{m} \mathrm{s}^{-1}$ ), linearity (LIN; \%) and amplitude of lateral head displacement $(\mathrm{ALH} ; \mu \mathrm{m})$ were assessed at different time points using a computer-assisted sperm analysis (CASA) system. Mean values were depicted in Table S1. TM was defined as the percentage of spermatozoa with a VCL above10 $\mu \mathrm{m} \mathrm{s}^{-1}$, and PM as the percentage of spermatozoa with a VCL above $25 \mu \mathrm{m} \mathrm{s}^{-1}$ and straightness (STR) above $80 \%$. Samples (5 $\mu 1$ sperm/sample) were loaded on a pre-warmed $\left(37^{\circ} \mathrm{C}\right)$ Makler counting chamber and examined in a phase contrast microscope (Nikon Eclipse 80i) equipped with a warmed stage $\left(37^{\circ} \mathrm{C}\right)$ and a Basler A302fs digital camera (Basler Vision Technologies, Ahrensburg, Germany) connected to a computer by an IEEE 1394 interface. Images were captured and further analysed using $\mathrm{SCA}^{\circledR}$ software. At least ten fields or 400 spermatozoa were recorded and assessed in each sample. Settings were adjusted to ram spermatozoa (25 frames/s, 20-90 $\mu \mathrm{m}^{2}$ for head area and VCL $>10 \mu \mathrm{m}$ $\mathrm{s}^{-1}$ to classify spermatozoa as motile).

\section{Mitochondrial activity, ROS production and apoptosis}

Several sperm parameters (mitochondrial activity, ROS production and apoptosis) were evaluated at different incubation times by flow cytometry. Samples were diluted to $5 \times 10^{6} \mathrm{sperm} / \mathrm{ml}$ in SOF-PVA-HEPES and stained using combinations of two fluorochromes. Mitochondrial activity was evaluated with $25 \mathrm{nM}$ of YO-PRO-1 and $100 \mathrm{nM}$ of Mitotracker Deep Red; ROS production with $12 \mu \mathrm{M}$ of PI and $5 \mu \mathrm{M}$ of CM- $\mathrm{H}_{2}$ DCFDA and apoptosis with $15 \mu \mathrm{M}$ of PI and $50 \mathrm{nM}$ of YO-PRO-1. Apoptosis and ROS production were immediately assessed with a FlowSight ${ }^{\circledR}$ flow cytometer (Amnis; Merck-Millipore, Germany) controlled with the INSPIRE ${ }^{\circledR}$ software (v.3), while mitochondrial activity was evaluated after incubating sperm samples for $15 \mathrm{~min}$ 
249 in the dark at $37^{\circ} \mathrm{C}$. All fluorochromes (Invitrogen; Barcelona, Spain) were excited with 250 a $488 \mathrm{~nm}$ solid state laser (20 mW intensity), except Mitotracker Deep Red, which was 251 excited with a $642 \mathrm{~nm}$ solid state laser (5 mW intensity).YO-PRO-1 and CM$252 \mathrm{H}_{2}$ DCFDA fluorescence were detected on channel $2(505-560 \mathrm{~nm})$ while PI 253 fluorescence was detected on channel 4 (595-642 nm) and Mitotracker Deep Red on 254 channel $11(642-740 \mathrm{~nm})$. A dot plot with the parameters aspect ratio versus area was 255 used to discriminate debris from spermatozoa during acquisition. The aspect ratio was 256 adjusted to $\leq 0.35$ and area to $\geq 50-\leq 400 \mu \mathrm{m}^{2}$ to acquire events compatible with ram 257 sperm morphology. A total of 5,000 spermatozoa were evaluated per sample. Raw data 258 were analysed with the IDEAS ${ }^{\circledR}$ software to obtain the proportion of apoptotic 259 spermatozoa (YO-PRO-1+/PI-) and the proportion of viable spermatozoa with active 260 mitochondria (Mitotracker+/ YO-PRO-1-) by scatter plots, and the mean fluorescence 261 intensity (MFI) of CM- $\mathrm{H}_{2}$ DCFDA by histograms. This latter variable indicates ROS 262 production in viable spermatozoa (PI-). Mean values were depicted in Table S2.

263 Protein tyrosine phosphorylation (pY)

264 Global protein tyrosine phosphorylation (pY) was assessed with the FlowSight ${ }^{\circledR}$ 265 flow cytometer following the procedure described by Peris-Frau et al. ${ }^{29}$ Briefly, samples 266 collected at different incubation times were fixed with $2 \%(\mathrm{v} / \mathrm{v})$ paraformaldehyde in 267 PBS at RT for $10 \mathrm{~min}$, washed and resuspended in $0.1 \%(\mathrm{v} / \mathrm{v})$ BD FACSTM 268 Permeabilizing Solution for $10 \mathrm{~min}$ at RT. Spermatozoa were then washed and blocked 269 with $10 \%$ (w/v) BSA in PBS (blocking buffer) for $30 \mathrm{~min}$ at $38.5^{\circ} \mathrm{C}$. After washing 270 again, spermatozoa were incubated with anti-phosphotyrosine monoclonal antibody 271 Clone $4 \mathrm{G} 10$ (1:300 dilution in blocking buffer) for $1 \mathrm{~h}$ at $38^{\circ} \mathrm{C}$. Subsequently, samples 272 were incubated with FITC-conjugated anti-mouse IgG antibody (1:300 dilution in 273 blocking buffer) for $1 \mathrm{~h}$ in the dark at $38^{\circ} \mathrm{C}$ and run through the flow cytometer. A 
274

275

276

277

278

279

280

281

282

283

284

285

286

287

288

289

290

291

292

293

294

295

296

297

298

negative control was obtained by incubation with IgG1-FITC (isotype from murine myeloma, clone MOPC 21; 1:300 dilution) instead of the primary antibody. At least 5,000 spermatozoa per sample were analysed and the percentage of spermatozoa showing green fluorescence (tyrosine-phosphorylated spermatozoa) was recorded in each sample (Figure S1).

\section{Statistical analysis}

Statistical analyses were performed using SPSS v. 23.0 (IBM corp., Chicago, USA). Data were checked for normality by the Shapiro-Wilk test and logarithmic transformation was applied when required. Three biological replicates per sample were assessed. $\mathrm{AB}+$, DNA methylation, \%DFI, HDS, apoptosis, mitochondrial activity, pY, TM, PM, VCL, LIN, ALH and ROS production were evaluated by a factorial ANOVA. The statistical model included the effect of treatments (incubation times in NC and CAP conditions), type of sample (fresh or cryopreserved spermatozoa) and replicates, as well as the interaction between treatments and type of sample. After obtaining significant interactions $(\mathrm{P}<0.05)$ between the treatments and the type of sample in the different parameters studied, these factors were studied separately for a better interpretation of the main effects. When main effects were significant $(\mathrm{P}<0.05)$, post hoc comparisons with Bonferroni correction were carried out. Values were expressed as non-transformed least square means \pm SEM. Although the different incubation times in CAP and NC were statistically analysed all together to determine the significance between them, the results obtained during the incubation period under CAP conditions were divided from the results obtained under $\mathrm{NC}$ conditions in the different figures for a better visualization of the dynamics changes produced during CAP or NC conditions.

Pearson correlation coefficients were calculated to estimate whether there were any association between the different sperm parameters evaluated. Correlations included 
299 all incubation times under CAP or NC conditions but were calculated separately for 300 fresh spermatozoa incubated under NC or CAP conditions and for cryopreserved 301 spermatozoa incubated under the same conditions. Significance was set to $\mathrm{P}<0.01$ for 302 correlations to avoid error type 1 due to the large number of correlations calculated at 303 once.

304 RESULTS

305 Aniline blue staining only increased during incubation of fresh and cryopreserved spermatozoa under capacitating conditions Incubation under NC conditions did not have any significant effect on chromatin condensation in either fresh or cryopreserved spermatozoa over time (Figure 3). Under CAP conditions, however, chromatin condensation decreased at certain incubation times. The highest $(\mathrm{P}<0.05)$ percentages of spermatozoa with decondensed chromatin $(\mathrm{AB}+)$ were recorded between 5 and $30 \mathrm{~min}$ in cryopreserved samples and between 180 and $240 \mathrm{~min}$ in fresh samples. Additionally, significant differences were observed between fresh and cryopreserved spermatozoa after 120 min under CAP conditions (Figure 3).

Chromatin integrity was not compromised during incubation of fresh and cryopreserved spermatozoa under capacitating and non-capacitating conditions

\section{but HDS increased during capacitation}

Neither media nor incubation time altered chromatin integrity, since the \%DFI

319 remained constant $(\mathrm{P}>0.05)$ throughout the entire incubation period under CAP and

320 NC conditions in both fresh and cryopreserved spermatozoa (Figure 4). However, when

321 the \%DFI of both types of samples was compared at different time points of incubation

322 under CAP and NC conditions, cryopreserved samples showed, in general, a higher

$323 \%$ DFI $(\mathrm{P}<0.05)$ than the fresh samples. 
On the other hand, the percentage of HDS only changed during the incubation

325

326

327

328

329

330

331

332

333

334

335

336

337

338

339

340

341

342

343

344

345

346

347

348

period under CAP conditions, depicting the highest values $(\mathrm{P}<0.05)$ from 5 to $30 \mathrm{~min}$ in cryopreserved samples and from 180 to $240 \mathrm{~min}$ in fresh samples (Figure 5). At these incubation times, significant differences were found between the percentage of HDS in fresh and cryopreserved samples.

The proportion of methylated spermatozoa only increased in cryopreserved spermatozoa after prolonged incubations under CAP and NC conditions

In fresh samples, the proportion of methylated spermatozoa did not change $(\mathrm{P}>$ 0.05) throughout the incubation period under CAP and NC conditions (Figure 6). However, in the cryopreserved samples, prolonged exposure to CAP conditions significantly increased the proportion of methylated spermatozoa after $60 \mathrm{~min}$. Although significant differences were not found under NC conditions $(\mathrm{P}>0.05)$, an extended incubation of $240 \mathrm{~min}$ also intensified the proportion of methylated spermatozoa in the cryopreserved samples. Moreover, DNA methylation of cryopreserved spermatozoa was generally higher compared to fresh spermatozoa during incubation, being statistically significant $(\mathrm{P}<0.05)$ after 30 min under CAP conditions and after 240 min under NC conditions.

\section{Correlations between nuclear variables and sperm quality parameters}

Chromatin decondensation $(\mathrm{AB}+)$ and $\mathrm{HDS}$ showed a positive correlation in fresh and cryopreserved spermatozoa with pY, total motility (TM), progressive motility (PM), VCL and ALH, but a negative correlation with $\mathrm{LIN}(\mathrm{P}<0.01)$ during the incubation period under CAP conditions (Tables 1 and 2). The strength of association between these variables was mostly moderate or strong and is depicted in Table $\mathbf{1}$ for 
$349 \mathrm{AB}+$ and in Table 2 for HDS. Furthermore, a positive correlation between $\mathrm{AB}+$ and 350 HDS was observed under CAP conditions, being moderate in fresh samples and strong 351 in cryopreserved $(\mathrm{P}<0.01)$. Regarding mitochondrial activity, this variable only 352 showed a positive and strong correlation with $\mathrm{AB}+$ and $\mathrm{HDS}$ in cryopreserved 353 spermatozoa incubated under CAP conditions. In contrast, ROS production and apoptosis were not significantly correlated $(\mathrm{P}>0.01)$ with HDS or $\mathrm{AB}+$ neither in fresh nor cryopreserved spermatozoa incubated under CAP conditions (Tables 1 and 2). Under NC conditions, all the sperm variables evaluated were not significantly correlated with $\mathrm{AB}+$ or HDS $(\mathrm{P}>0.01)$ neither in fresh nor cryopreserved spermatozoa (Tables 1 and 2).

The correlations between sperm DNA methylation and other sperm variables are shown in Table 3. No significant correlations $(\mathrm{P}>0.01)$ were found between DNA methylation and nuclear variables $(\% \mathrm{DFI}, \mathrm{HDS}$ and $\mathrm{AB}+)$ or between DNA methylation and diverse sperm quality parameters (pY, TM, PM, VCL, ALH, LIN, mitochondrial activity and ROS production) in fresh and cryopreserved spermatozoa incubated under CAP and NC conditions. However, DNA methylation was positively correlated with apoptosis $(\mathrm{P}<0.01)$ but only in cryopreserved spermatozoa incubated under CAP conditions.

\section{DISCUSSION}

Capacitation of mammalian spermatozoa is a complex event that involves a set

370 of functional, structural, and molecular changes. ${ }^{19,20,45}$ However, only a few studies 371 have investigated the effect of sperm capacitation on the chromatin structure. These 372 studies found that spermatozoa showed a less compacted chromatin, sperm DNA 373 integrity remained unchanged and the disulphide bonds between protamines decreased 
374 during in vitro capacitation. ${ }^{21-24,46-48}$ Nevertheless, to the best of our knowledge, no

375 previous studies have investigated sperm DNA methylation during this event. In line

376 with these findings, our results revealed that fresh and cryopreserved ram spermatozoa

377 exhibited a lower chromatin condensation at certain time points during in vitro

378 capacitation, while DNA integrity remained constant during this event. In addition,

379 DNA methylation only increased in cryopreserved ram spermatozoa incubated under

380 capacitating conditions, but after $60 \mathrm{~min}$.

381 Sperm chromatin condensation can be evaluated rapidly with aniline blue (AB).

382 This cytochemical dye selectively stains persisting lysine-rich histones ${ }^{49,50}$ and has been

383 widely used to identify an excessive histone retention in the chromatin of mature

384 spermatozoa, which has been related to infertility, poor fertilization rates and morphological defects in the sperm head. ${ }^{10,14,51}$ However, a lower sperm chromatin condensation detected with $\mathrm{AB}$ does not always involve an abnormal histone content.

De Lamirande et al. ${ }^{22}$ suggested that during capacitation, nuclear histones could be reoriented, facilitating $\mathrm{AB}$ access to them. Such chromatin decondensation should be moderate, because, beyond certain levels, a high or null chromatin condensation could compromise the fertilizing potential of spermatozoa. ${ }^{15,17,24}$ In line with previous studies conducted in bull and human sperm, ${ }^{22-24}$ our results for $\mathrm{AB}$ revealed that sperm chromatin condensation decreased during in vitro capacitation of ram spermatozoa. This variation in the chromatin condensation level was initiated in cryopreserved ram

394 spermatozoa earlier than in fresh, reaching the highest percentages of spermatozoa with 395 decondensed chromatin $(\mathrm{AB}+)$ at 5-30 $\mathrm{min}$ in cryopreserved samples and at 180-240 min in fresh samples. However, such changes in chromatin condensation were not

397 observed under NC conditions. Earlier studies on sperm nuclear decondensation 398 reported that it only occurs after changes in membrane fluidity and permeability, like 
399 those observed after cryopreservation or during sperm capacitation. ${ }^{35,52-54}$ But apart 400 from membrane destabilisation, decondensing factors are apparently required to induce 401 sperm nuclear decondensation..$^{35,54}$ Therefore, the differences found between CAP and 402 NC conditions in our study could probably be explained by the presence of certain 403 decondensing factors in the capacitating medium. In addition, we speculate that changes 404 in membrane stability during cryopreservation might have accelerated the nuclear 405 decondensation of cryopreserved ram spermatozoa during CAP conditions. Romanato et al. ${ }^{54}$ proposed that some glycosaminoglycans, specially heparan 407 sulphate, which has been found in oocytes, could act as decondensing factors once 408 spermatozoa penetrate the oocytes. Likewise, glycosaminoglycans have also been found 409 in the oviductal fluid of many species, ${ }^{55}$ participating in sperm capacitation under 410 physiological conditions. ${ }^{56}$ In small ruminants, in vitro capacitation is frequently 411 attained after incubating spermatozoa in a capacitating medium supplemented with 412 oestrous sheep serum (ESS). ${ }^{38,39,57}$ This capacitating agent (ESS) contains several 413 glycosaminoglycans present in the oviductal fluid, including heparan sulphate ${ }^{58}$ and was 414 not added to the NC medium in our experiment, supporting the hypothesis that sperm 415 chromatin decondensation could be induced by glycosaminoglycans under CAP 416 conditions.

417 Incorrect or looser chromatin compaction usually entails an altered 418 histone:protamine ratio and, more specifically, protamine deficiency, increasing sperm 419 DNA damage. ${ }^{12}$ However, when we evaluated sperm DNA integrity during the time 420 course of in vitro capacitation with the SCSA, our results showed that the \%DFI 421 remained constant during the entire incubation period under CAP conditions either in 422 fresh or cryopreserved spermatozoa. In line with our findings, earlier studies also 423 reported that sperm DNA integrity was not adversely affected during in vitro 
424 capacitation. ${ }^{22,47,48}$ These results suggest that this partial chromatin decondensation

425 observed in fresh and cryopreserved ram spermatozoa takes place during physiological

426 processes, such as sperm capacitation, without altering DNA integrity. Our results also

427 revealed that cryopreserved spermatozoa showed a higher \%DFI than fresh

428 spermatozoa, which is not surprising because cryopreservation is known to exert a

429 negative effect on sperm DNA integrity. ${ }^{59,60}$

430 Another nuclear parameter evaluated with SCSA was HDS. According to

431 Evenson, ${ }^{61}$ HDS represents the proportion of immature spermatozoa with a defective

432 chromatin structure (abnormal histone-protamine content). This abnormal histone-

433 protamine content implies a lower chromatin condensation, facilitating the access of AO

434 staining to double-stranded DNA (intact DNA). ${ }^{62}$ However, chromatin decondensation

435 of ram spermatozoa during in vitro capacitation could be more related to conformational

436 changes in the chromatin structure rather than to abnormal histone-protamine content, ${ }^{61}$

437 as has been suggested by De Lamirande et al. ${ }^{22}$ Our results showed that similar to AB+,

438 HDS increased at certain incubation times but only during in vitro capacitation,

439 occurring in cryopreserved spermatozoa faster (at 5-30 min) than in fresh spermatozoa

440 (at 180-240 min). Furthermore, a positive correlation was observed between HDS and

$441 \mathrm{AB}+$ under $\mathrm{CAP}$ conditions in fresh and cryopreserved spermatozoa. These finding

442 suggest that HDS might represent, as $\mathrm{AB}+$, the proportion of spermatozoa with a less

443 condensed chromatin during in vitro capacitation. Although the mechanisms underlying

444 sperm chromatin decondensation are yet unclear during capacitation, these changes in

445 sperm nuclear compaction could facilitate the events surrounding and following 446 fertilisation. ${ }^{22}$

447 In addition, based on the different correlations found under CAP conditions 448 between $\mathrm{HDS}, \mathrm{AB}+$ and the diverse sperm parameters assessed in this study, those 
449 changes observed in the chromatin condensation were seemingly linked to changes in

450 the motility pattern and in tyrosine phosphorylation during CAP conditions either in

451 fresh or cryopreserved ram spermatozoa as well as to variations in mitochondrial

452 activity in the case of cryopreserved spermatozoa, but not to apoptosis, oxidative stress,

453 DNA damage or epigenetic changes. These findings suggest that during the sperm

454 activation window, chromatin decondensation occurs in parallel to the other widely

455 reported capacitation-associated changes. ${ }^{28,63-67}$ Moreover, our results differed from

456 those related to male infertility, in which sperm samples had a high \%DFI and DNA

457 damage was linked to abnormal chromatin packaging. ${ }^{16,68,69}$

458 We also explored whether cryopreservation and incubation under CAP

459 conditions induced epigenetic changes. DNA methylation is an important epigenetic

460 mechanism that is transmitted to the next generation and modulates gene expression

461 during embryogenesis and gametic imprinting. ${ }^{2}$ Previous studies have shown that

462 freezing-thawing procedures can alter the pattern of sperm DNA methylation. ${ }^{34,70}$

463 Aurich et al. ${ }^{34}$ reported that DNA methylation increased in stallion spermatozoa after

464 cryopreservation, while other authors found that sperm DNA methylation decreased

465 after cryopreservation in rooster spermatozoa. ${ }^{70}$ In our study, sperm DNA methylation

466 increased after cryopreserved ram spermatozoa were incubated for 60, 180 and 240 min

467 under capacitating conditions, but not immediately after thawing. Differences between

468 species, methodologies, cryopreservation media and sperm treatments could be the

469 reason for such discrepancies. Perturbations in sperm DNA methylation have been

470 associated with male infertility, embryogenesis defects and pregnancy loss. ${ }^{7,71}$

471 However, it is unclear whether these drastic changes in sperm DNA methylation imply

472 only hypomethylation, ${ }^{44}$ hypermethylation ${ }^{72}$ or even both alterations in different gene

473 regions, ${ }^{9}$ which results in no differences in global methylation. Similar inconsistencies 
474 arise when methylation is correlated with other sperm quality parameters. ${ }^{73-75}$ Our

475 results showed that sperm DNA methylation was only correlated with apoptosis in 476 cryopreserved ram spermatozoa incubated under CAP conditions. A similar correlation 477 was previously found in spermatozoa with poor quality, which could be indicative of 478 defective spermatogenesis. ${ }^{76}$ However, in the present study DNA methylation and 479 apoptosis only increased after certain incubation times under CAP conditions in 480 cryopreserved spermatozoa, probably as a result of an early response to oxidative 481 stress, ${ }^{77}$ but further investigations are required to better understand this correlation in 482 our study.

483 In summary, our results revealed that sperm chromatin condensation was 484 progressively modified over the incubation period under CAP conditions in fresh and 485 cryopreserved ram spermatozoa while DNA integrity remained constant. In addition, 486 prolonged incubations (60-240 min) under CAP conditions resulted in epigenetic 487 changes in cryopreserved ram spermatozoa. Cryopreserved spermatozoa exhibited less 488 condensed chromatin earlier than fresh spermatozoa during capacitation probably as a 489 result of those changes induced in membrane stability by the cryopreservation process. 490 Finally, the correlations found in our study suggest that chromatin decondensation may 491 occur simultaneously to other functional changes associated with sperm capacitation. In 492 addition, these changes in sperm chromatin condensation do not seem to be related to 493 apoptosis, oxidative stress or DNA damage. Further studies are required to better 494 understand the mechanisms involved in these chromatin alterations observed during 495 sperm capacitation. 
498 PFP and DAMC were supported by a University of Castilla-La Mancha scholarship.

499 MIC and AMM were supported by a Ministry of Economy and Competitiveness 500 scholarship. The study was supported by grants from ALF-Research (Region 501 Östergötland, LIO-698951), FORSS (Forskningsrådet i Sydöstra Sverige, 473121 and 502 745971), Lions Forskningsfond (DNRLIU-2016-00641), Linköping and the Swedish 503 Research Council FORMAS, Stockholm (Project 2017-00946 and Project 2019-00288) 504 and by the MINECO (AGL2013-48421-R). Sperm nuclear parameters were evaluated in 505 the Department of Biomedical and Clinical Sciences (BKV) from the Faculty of 506 Medicine in Linköping (Sweden) after preparing samples in the laboratory of SaBio 507 IREC (ETSIAM, Albacete, Spain).

508

\section{CONFLICT OF INTEREST}

510 The authors declare that there is no conflict of interest.

\section{AUTHOR CONTRIBUTIONS}

513 Peris-Frau P, Álvarez-Rodríguez M, Martín-Maestro A, Iniesta-Cuerda M, Sánchez514 Ajofrín I and Medina-Chávez DA took the samples, performed the experiments and 515 made the database. Garde JJ, Rodriguez-Martinez H, Villar M and Soler AJ performed 516 the statistical analyses and reviewed the final manuscript and Soler AJ designed the 517 study.

\section{REFERENCES}

520 1. Castillo J, Jodar M, Oliva R. The contribution of human sperm proteins to the development and epigenome of the preimplantation embryo. Hum Reprod. 
522

523

524

525

526

527

528

529

530

531

532

533

534

535

536

537

538

539

540

541

542

543

544

545

546

2018;24:535-55.

2. Champroux A, Cocquet J, Henry-Berger J, Drevet JR, Kocer A. A decade of exploring the mammalian sperm epigenome: paternal epigenetic and transgenerational inheritance. Front Cell Dev Biol. 2018;6:50.

3. Yamauchi Y, Shaman JA, Ward WS. Non-genetic contributions of the sperm nucleus to embryonic development. Asian J Androl. 2011;13(1):31-5.

4. Barrachina F, Soler-Ventura A, Oliva R, Jodar M. Sperm nucleoproteins (histones and protamines). A Clinician's Guide to Sperm DNA and Chromatin Damage. 2018. 31-51 p.

5. Wykes SM, Krawetz SA. The structural organization of sperm chromatin. J Biol Chem. 2003;278(32):29471-7.

6. Hammoud SS, Nix DA, Zhang H, Purwar J, Carrell DT, Cairns BR. Distinctive chromatin in human sperm packages genes for embryo development. Nature. 2009;460(7254):473-8.

7. Kumar M, Kumar K, Jain S, Hassan T, Dada R. Novel insights into the genetic and epigenetic paternal contribution to the human embryo. Clinics. 2013;68(Suppl 1):5-14.

8. Simon L, Zini A, Dyachenko A, Ciampi A, Carrell D. A systematic review and meta-analysis to determine the effect of sperm DNA damage on in vitro fertilization and intracytoplasmic sperm injection outcome. Asian J Androl. 2017;19(1):80-90.

9. Verma A, Rajput S, De S, Kumar R, Chakravarty, Atish Kumar Datta TK. Genome-wide profiling of sperm DNA methylation in relation to buffalo ( Bubalus bubalis ) bull fertility. Theriogenology. 2014;82(2):750-9.

10. Marchiani S, Tamburrino L, Benini F, Fanfani L, Dolce R, Rastrelli G, et al. 
547 Chromatin protamination and catsper expression in spermatozoa predict clinical $548 \quad$ outcomes after assisted reproduction programs. Sci Rep. 2017;7:15122.

549 11. Ge S, Lin S, Zhao Z, Sun Q. Epigenetic dynamics and interplay during spermatogenesis and embryogenesis : implications for male fertility and offspring health. Oncotarget. 2017;8(32):53804-18.

552 12. Miller D, Brinkworth M, Iles D. Paternal DNA packaging in spermatozoa: more than the sum of its parts? DNA, histones, protamines and epigenetics. Reproduction. 2010;139(287):301.

13. Balhorn R. A model for the structure of chromatin in mammalian sperm. J Cell Biol. 1982;93(2):298-305.

14. Sellami A, Chakroun N, Zarrouk S Ben, Sellami H, Kebaili S, Rebai T, et al. Assessment of chromatin maturity in human spermatozoa: useful aniline blue assay for routine diagnosis of male infertility. Adv Urol. 2013;2013:578631.

15. Rodriguez H, Ohanian C, Bustos-Obregon E. Nuclear chromatin decondensation of spermatozoa in vitro: a method for evaluating the fertilizing ability of ovine semen. Int J Androl. 1985;8:147-58.

16. Agarwal A, Said TM. Role of sperm chromatin abnormalities and DNA damage in male infertility. Hum Reprod Update. 2003;9(4):331-45.

17. Gopalkrishnan K, Hinduja IN, Anand Kumar TC. In vitro decondensation of nuclear chromatin of human spermatozoa: Assessing fertilizing potential. Andrology. 1991;27(1):43-50.

18. Galotto C, Cambiasso MY, Julianelli VL, Valzacchi GJR, Rolando RN, Rodriguez ML, et al. Human sperm decondensation in vitro is related to cleavage rate and embryo quality in IVF. J Assist Reprod Genet. 2019;36(11):2345-55.

19. Austin CR. The capacitation of the mammalian sperm. Nature. 1952;170:326. 
572 20. Stival C, Molina CP, Paudel B, Buffone MG, Visconti PE, Krapf D. Sperm

573

574

575

576

577

578

579

580

581

582

583

584

585

586

587

588

589

590

591

592

593

594

595

596 capacitation and acrosome reaction in mammalian sperm. In: Sperm Acrosome Biogenesis and Function During Fertilization. 2016. p. 93-106.

21. Betarelli RP, Rocco M, Yeste M, Fernández-Novell JM, Placci A, Azevedo Pereira B, et al. The achievement of boar sperm in vitro capacitation is related to an increase of disrupted disulphide bonds and intracellular reactive oxygen species levels. Andrology. 2018;6:781-97.

22. De Lamirande E, San Gabriel MC, Zini A. Human sperm chromatin undergoes physiological remodeling during in vitro capacitation and acrosome reaction. $\mathrm{J}$ Androl. 2012;33(5):1025-35.

23. Campos MNG, Jacomini JO, Sampaio GSL, Pinto DA, Alves BG, Lemos MS. Chromatin condensation and morphometry of the bovine sperm head after in vitro sperm selection and capacitation. J Appl Anim Res. 2013;41(1):87-92.

24. Royere D, Hamamah S, Nicolle JC, Lansac J. Does in vitro capacitation alter chromatin stability of ejaculated human spermatozoa? cytochemical studies. Mol Reprod Dev. 1991;28(2):177-82.

25. Pérez-Cerezales S, Laguna-Barraza R, De Castro AC, Sánchez-Calabuig MJ, Cano-Oliva E, De Castro-Pita FJ, et al. Sperm selection by thermotaxis improves ICSI outcome in mice. Sci Rep. 2018;8:2902.

26. Perez LJ, Valcárcel A, De Las Heras MA, Moses D, Baldassarre H. Evidence that frozen/thawed ram spermatozoa show accelerated capacitation in vitro as assessed by chlotetracycline asssay. Theriogenology. 1996;46:131-40.

27. Garde JJ, Gutiérrez-Adán A, Artiga CG, Vázquez I. Influence of freezing process on "in vitro" capacitation of ram semen. Theriogenology. 1993;39:225.

28. Peris-Frau P, Martín-Maestro A, Iniesta-Cuerda M, Sánchez-Ajofrín I, Cesari A, 
597

598

599

600

601

602

603

604

605

606

607

608

609

610

611

612

613

614

615

616

617

618

619

620

621

Garde JJ, et al. Cryopreservation of ram sperm alters the dynamic changes associated with in vitro capacitation. Theriogenology. 2020;145:100-8.

29. Peris-Frau P, Martín-Maestro A, Iniesta-Cuerda M, Sánchez-Ajofrín I, MateosHernández L, Garde JJ, et al. Freezing-thawing procedures remodel the proteome of ram sperm before and after in vitro capacitation. Int J Mol Sci. 2019 Sep 17;20(18):4596.

30. Bailey JL, Bilodeau JF, Cormier N. Semen cryopreservation in domestic animals: a damaging and capacitating phenomenon. J Androl. 2000;21(1):1-7.

31. Satorre MM, Breininger E, Beconi MT, Beorlegui NB. Protein tyrosine phosphorylation under capacitating conditions in porcine fresh spermatozoa and sperm cryopreserved with and without alpha tocopherol. Andrologia. 2009;41(3):184-92.

32. Pini T, Leahy T, de Graaf SP. Sublethal sperm freezing damage: Manifestations and solutions. Theriogenology. 2018;118:172-81.

33. Flores E, Ramió-Lluch L, Bucci D, Fernández-Novell JM, Peña A, RodríguezGil JE. Freezing-thawing induces alterations in histone H1-DNA binding and the breaking of protein-DNA disulfide bonds in boar sperm. Theriogenology. 2011;76(8):1450-64.

34. Aurich C, Schreiner B, Ille N, Alvarenga M, Scarlet D. Cytosine methylation of sperm DNA in horse semen after cryopreservation. Theriogenology. 2016;86(5):1347-52.

35. Jager S, Wijchman J, Kremer J. Studies on the decondensation of human, mouse, and bull sperm nuclei by heparin and other polyanions. J Exp Zool. $1990 ; 256(3): 315-22$.

36. Takahashi Y, First NL. In vitro development of bovine one-cell embryos: 
622

623

624

625

626

627

628

629

630

631

632

633

634

635

636

637

638

639

640

641

642

643

644

645

646

Influence of glucose, lactate, pyruvate, amino acids and vitamins.

Theriogenology. 1992;37:963-78.

37. Cognié A, Poulin N, Locatelli Y, Pascal M. State-of-the-art production, conservation and transfer of in-vitro -produced embryos in small ruminants. Reprod Fertil Dev. 2004;16:437-45.

38. Huneau D, Crozet N, Ahmed-Ali M. Estrous sheep serum as a potent agent for ovine IVF: effect on cholesterol efflux from spermatozoa and the acrosome reaction. Theriogenology. 1994;42:1017-28.

39. García-Álvarez O, Maroto-Morales A, Jiménez-Rabadán P, Ramón M, Del Olmo E, Iniesta-Cuerda M, et al. Effect of different media additives on capacitation of frozen-thawed ram spermatozoa as a potential replacement for estrous sheep serum. Theriogenology. 2015;84(6):948-55.

40. Visconti PE, Bailey JL, Moore GD, Pan D, Olds-Clarke P, Kopf GS.

Capacitation of mouse spermatozoa. I. Correlation between the capacitation state and protein tyrosine phosphorylation. Development. 1995;121(4):1129-37.

41. Grasa P, Colas C, Gallego M, Monteagudo L, Muiño-Blanco T, Cebrián-Pérez JÁ. Changes in content and localization of proteins phosphorylated at tyrosine, serine and threonine residues during ram sperm capacitation and acrosome reaction. Reproduction. 2009;137(4):655-67.

42. Shamsi MB, Imam SN, Dada R. Sperm DNA integrity assays: diagnostic and prognostic challenges and implications in management of infertility. J Assist Reprod Genet. 2011;28:1073-85.

43. Evenson DP, Larson KL, Jost LK. Sperm Chromatin Structure Assay: Its clinical use for detecting sperm DNA fragmentation in male infertility and comparisons with other techniques. J Androl. 2002;23(1):25-43. 
647 44. Benchaib M, Ajina M, Lornage J, Niveleau A, Durand P, Guérin JF. Quantitation 648

49. Banaszewska D, Andraszek K, Biesiada-Drzazga B. Evaluation of sperm chromatin structure in boar semen. Bull Vet Inst Pulawy. 2015;59(2):271-7.

50. Andraszek K, Banaszewska D, Czubaszek M, Wójcik E, Szostek M. Comparison of different chromatin staining techniques for bull sperm. Arch Anim Breed. 2014;57(1):1-15.

51. Vieytes AL, Cisale HO, Ferrari MR. Relationship between the nuclear morphology of the sperm of 10 bulls and their fertility. Vet Rec. 
672

673

674

675

676

677

678

679

680

681

682

683

684

685

686

687

688

689

690

691

692

693

694

695

696

2008;163(21):625-9.

52. Gadella BM, Tsai P, Boerke A, Brewis IA. Sperm head membrane reorganisation during capacitation. Int J Dev Biol. 2008;52:473-80.

53. Julianelli V, Farrando B, Alvarez Sedó C, Calvo L, Romanato M, Calvo JC. Heparin enhances protamine disulfide bond reduction during in vitro decondensation of human spermatozoa. Hum Reprod. 2012;27(7):1930-8.

54. Romanato M, Cameo MS, Bertolesi G, Baldini C, Calvo JC, Calvo L. Heparan sulphate: a putative decondensing agent for human spermatozoa in vivo. Hum Reprod. 2003;18(9):1868-73.

55. Bergqvist AS, Rodríguez-Martínez H. Sulphated glycosaminoglycans (S-GAGs) and syndecans in the bovine oviduct. Anim Reprod Sci. 2006;93:46-60.

56. Parrish JJ, Susko-Parrish JL, Handrow RR, Sims MM, First NL. Capacitation of bovine spermatozoa by oviduct fluid. Biol Reprod. 1989;40:1020-5.

57. Cognie Y, Baril G, Poulin N, Mermillod P. Current status of embryo technologies in sheep and goat. Theriogenology. 2003;59:171-88.

58. Lu H, Mcdowell LM, Studelska DR, Zhang L. Glycosaminoglycans in human and bovine serum: detection of twenty-four heparan sulfate and chondroitin sulfate motifs including a novel sialic acid-modified chondroitin sulfate linkage hexasaccharide. Glycobiol Insights. 2010;2:13-28.

59. Peris SI, Bilodeau JF, Dufour M, Bailey JL. Impact of cryopreservation and reactive oxygen species on DNA integrity, lipid peroxidation, and functional parameters in ram sperm. Mol Reprod Dev. 2007;74:878-92.

60. Ugur MR, Abdelrahman AS, Evans HC, Gilmore AA, Hitit M, Arifiantini RI, et al. Advances in cryopreservation of bull sperm. Front Vet Sci. 2019;6:268.

61. Evenson DP. The Sperm Chromatin Structure Assay (SCSA $\left.{ }^{2}\right)$ and other sperm 
697

698

699

700

701

702

703

704

705

706

707

708

709

710

711

712

713

714

715

716

717

718

719

720

721

DNA fragmentation tests for evaluation of sperm nuclear DNA integrity as related to fertility. Anim Reprod Sci. 2016;169:56-75.

62. Jerre E, Bungum M, Evenson D, Giwercman A. Sperm chromatin structure assay high DNA stainability sperm as a marker of early miscarriage after intracytoplasmic sperm injection. Fertil Steril. 2019;112(1):46-53.

63. Grasa P, Cebrián-Pérez JA, Muiño-Blanco T. Signal transduction mechanisms involved in in vitro ram sperm capacitation. Reproduction. 2006;132(5):721-32.

64. García-Álvarez O, Maroto-Morales A, Ramón M, Del Olmo E, Jiménez-Rabadán P, Fernández-Santos MR, et al. Dynamics of sperm subpopulations based on motility and plasma membrane status in thawed ram spermatozoa incubated under conditions that support in vitro capacitation and fertilisation. Reprod Fertil Dev. 2014;26(5):725-32.

65. Visconti PE, Bailey JL, Moore GD, Pan D, Olds-clarke P, Kopf GS. Capacitation of mouse spermatozoa I . Correlation between the capacitation state and protein tyrosine phosphorylation. Development. 1995;121:1129-37.

66. Ferramosca A, Zara V. Bioenergetics of mammalian sperm capacitation. Biomed Res Int. 2014;2014:902953.

67. Mortimer ST, Maxwell WMC. Kinematic definition of ram sperm hyperactivation. Reprod Fertil Dev. 1999;11:25-30.

68. Patankar A, Parte P. Sperm chromatin compaction and male infertility. In: Male Infertility: Understanding, Causes and Treatment. 2017. p. 295-315.

69. Simon L, Castillo J, Oliva R, Lewis SEM. Relationships between human sperm protamines, DNA damage and assisted reproduction outcomes. Reprod Biomed Online. 2011;23(6):724-34.

70. Salehi M, Mahdavi AH, Sharafi M, Shahverdi A. Cryopreservation of rooster 
semen: Evidence for the epigenetic modifications of thawed sperm. Theriogenology. 2020;142:15-25.

71. Jenkins TG, Carrell DT. Dynamic alterations in the paternal epigenetic landscape following fertilization. Front Genet. 2012;3:1-8.

72. Hammoud SS, Purwar J, Pflueger C, Cairns BR, Carrell DT. Alterations in sperm DNA methylation patterns at imprinted loci in two classes of infertility. Fertil Steril. 2010;94(5):1728-33.

73. Montjean D, Zini A, Ravel C, Belloc S, Dalleac A, Copin H, et al. Sperm global DNA methylation level: Association with semen parameters and genome integrity. Andrology. 2015;3(2):235-40.

74. Cassuto NG, Montjean D, Siffroi J, Bouret D, Marzouk F, Copin H, et al. Different levels of DNA methylation detected in human sperms after morphological selection using high magnification microscopy. Biomed Res Int. 2016;2016:6372171.

75. Benchaib M, Braun V, Ressnikof D, Lornage J, Durand P, Niveleau A, et al. Influence of global sperm DNA methylation on IVF results. Hum Reprod. 2005;20(3):768-73.

76. Barzideh J, Scott RJ, Aitken RJ. Analysis of the global methylation status of human spermatozoa and its association with the tendency of these cells to enter apoptosis. Andrologia. 2013;45:424-9.

77. Doshi T, Mehta SS, Dighe V, Balasinor N, Vanage G. Hypermethylation of estrogen receptor promoter region in adult testis of rats exposed neonatally to bisphenol A. Toxicology. 2011;289:74-82. 
748

749

750

751

752

753 
755

756

757

758

759

760

761

762

763

764

765

766

767

768

769

770

771

772

773

774

775

776

777

778

\section{FIGURE LEGENDS}

Figure 1. Ram spermatozoa stained with aniline blue (AB). (A) Unstained nuclei (AB-) indicated normal sperm chromatin condensation, while (B) blue-stained nuclei indicated chromatin decondensation $(\mathrm{AB}+)$.

Figure 2. Ram spermatozoa showing DNA methylation after 5-methylcytosine (5-mc) immunostaining.(A) Spermatozoa with detectable levels of DNA methylation showed green fluorescence (Alexa Fluor 488) at their heads at 100x magnification and were classified as methylated spermatozoa, while (B) spermatozoa showing no fluorescence revealed no detectable levels of DNA methylation.

Figure 3. Changes in the proportion of fresh and cryopreserved spermatozoa showing chromatin decondensation $(\mathrm{AB}+)$ during the incubation period under capacitating (CAP) and non-capacitating (NC) conditions. The mean percentage of $\mathrm{AB}+$ spermatozoa \pm SEM at each time point was illustrated in the figure. Different letters represent significant differences $(\mathrm{P}<0.05)$ among incubation times. Uppercase letters were used for cryopreserved spermatozoa and lowercase letters for fresh spermatozoa. $\ddagger$ Denotes significant differences $(\mathrm{P}<0.05)$ between fresh and cryopreserved samples.

Figure 4. Changes in the proportion of fresh and cryopreserved spermatozoa with DNA fragmentation $(\% \mathrm{DFI})$ during the incubation period under capacitating (CAP) and noncapacitating (NC) conditions. The mean percentage of $\% \mathrm{DFI} \pm$ SEM at each time point was depicted in the figure. $\ddagger$ Indicates significant differences $(\mathrm{P}<0.05)$ between fresh and cryopreserved spermatozoa. Statistical differences were not $(\mathrm{P}>0.05)$ found among incubation times neither in fresh nor cryopreserved samples.

Figure 5. Changes in the proportion of fresh and cryopreserved spermatozoa with high DNA stainability (HDS) during the incubation period under capacitating (CAP) and 
779 non-capacitating (NC) conditions. The mean percentage of HDS \pm SEM at each time

780 point was illustrated in the figure. Different letters indicate significant differences $(\mathrm{P}<$

781 0.05) among incubation times. Uppercase letters were used for cryopreserved

782 spermatozoa and lowercase for fresh spermatozoa. $\ddagger$ Denotes significant differences (P

$783<0.05)$ between fresh and cryopreserved spermatozoa.

784 Figure 6. Changes in the proportion of fresh and cryopreserved spermatozoa showing

785 DNA methylation during the incubation period under capacitating (CAP) and non-

786 capacitating (NC) conditions. The mean percentage of DNA methylated spermatozoa \pm

787 SEM at each time point was depicted in the figure. Different letters represent significant

788 differences $(\mathrm{P}<0.05)$ among incubation times in cryopreserved samples. In fresh

789 samples, DNA methylation did not change significantly $(\mathrm{P}>0.05)$ over time. $\ddagger$

790 Indicates significant differences $(\mathrm{P}<0.05)$ between fresh and cryopreserved

791 spermatozoa.

792

793 
795

796

798

799 797 variables in fresh and cryopreserved spermatozoa incubated under capacitating (CAP) and non-

\section{TABLES}

Table 1. Correlation coefficients between chromatin decondensation $(\mathrm{AB}+)$ and several capacitating (NC) conditions. Correlations were estimated considering all incubation times under CAP or NC conditions.

\begin{tabular}{|c|c|c|c|c|}
\hline \multirow{3}{*}{ Variables $^{\mathrm{a}}$} & \multicolumn{4}{|c|}{$\mathrm{AB}+(\%)^{\mathrm{b}}$} \\
\hline & \multicolumn{2}{|c|}{ Fresh sperm } & \multicolumn{2}{|c|}{ Cryopreserved sperm } \\
\hline & CAP & $\mathrm{NC}$ & CAP & $\mathrm{NC}$ \\
\hline HDS (\%) & $0.49 *$ & 0.27 & $0.75^{*}$ & 0.24 \\
\hline DFI $(\%)$ & -0.46 & -0.33 & -0.44 & -0.28 \\
\hline pY (\%) & $0.87 *$ & 0.45 & $0.50^{*}$ & 0.24 \\
\hline $\mathrm{TM}(\%)$ & $0.46^{*}$ & -0.70 & $0.83 *$ & -0.78 \\
\hline PM (\%) & $0.50 *$ & -0.62 & $0.81 *$ & -076 \\
\hline $\operatorname{VCL}\left(\mu \mathrm{m} \mathrm{s}^{-1}\right)$ & $0.82 *$ & -0.13 & $0.72 *$ & 0.16 \\
\hline LIN (\%) & $-0.76^{*}$ & -0.52 & $-0.70 *$ & -0.21 \\
\hline $\mathrm{ALH}(\mu \mathrm{m})$ & $0.76^{*}$ & -0.10 & $0.72 *$ & 0.26 \\
\hline Mitochondrial activity (\%) & 0.50 & -0.47 & $0.79 *$ & -0.43 \\
\hline ROS (MFI) & -0.33 & -0.56 & -0.32 & -0.08 \\
\hline Apoptotic sperm (\%) & -0.20 & -0.31 & -0.14 & 0.05 \\
\hline
\end{tabular}

${ }^{a}$ HDS: percentage of spermatozoa with high DNA stainability; DFI: percentage of spermatozoa with DNA fragmentation index values higher than 25\%; pY: percentage of tyrosine phosphorylated spermatozoa; TM: percentage of total motility; PM: percentage of live spermatozoa with progressive motility; VCL: curvilinear velocity; LIN: linearity coefficient; ALH: amplitude of lateral head displacement; Mitochondrial activity: percentage of live spermatozoa with active mitochondria; ROS: mean fluorescence intensity (MFI) of reactive oxygen species produced by live spermatozoa; Apoptotic sperm: percentage of spermatozoa showing apoptosis.

${ }^{\mathrm{b}} \mathrm{AB}$ positives: percentage of spermatozoa showing chromatin decondensation. 
819 Table 2. Correlation coefficients between spermatozoa with high DNA stainability (HDS) and 820 several variables in fresh and cryopreserved spermatozoa incubated under capacitating (CAP) 821 and non-capacitating (NC) conditions. Correlations were estimated considering all incubation 822 times under CAP or NC conditions.

\begin{tabular}{|c|c|c|c|c|}
\hline \multirow{3}{*}{ Variables $^{\mathrm{a}}$} & \multicolumn{4}{|c|}{$\operatorname{HDS}(\%)^{\mathrm{b}}$} \\
\hline & \multicolumn{2}{|c|}{ Fresh sperm } & \multicolumn{2}{|c|}{ Cryopreserved sperm } \\
\hline & CAP & $\mathrm{NC}$ & CAP & $\mathrm{NC}$ \\
\hline $\mathrm{AB}+(\%)$ & $0.49 *$ & 0.27 & $0.75^{*}$ & 0.24 \\
\hline DFI (\%) & -0.42 & -0.41 & -0.44 & -0.17 \\
\hline pY $(\%)$ & $0.64 *$ & 0.40 & $0.52 *$ & 0.29 \\
\hline TM $(\%)$ & $0.41 *$ & 0.48 & $0.84 *$ & -0.79 \\
\hline PM (\%) & $0.51 *$ & 0.46 & $0.86^{*}$ & -0.67 \\
\hline $\operatorname{VCL}\left(\mu \mathrm{m} \mathrm{s}^{-1}\right)$ & $0.71 *$ & 0.45 & $0.79 *$ & 0.34 \\
\hline LIN (\%) & $-0.73^{*}$ & -0.31 & $-0.64^{*}$ & -0.10 \\
\hline $\mathrm{ALH}(\mu \mathrm{m})$ & $0.78 *$ & 0.34 & $0.79 *$ & 0.16 \\
\hline Mitochondrial activity (\%) & 0.59 & -0.19 & $0.87^{*}$ & -0.35 \\
\hline ROS (MFI) & -0.36 & -0.60 & -0.35 & -0.08 \\
\hline Apoptotic sperm (\%) & 0.14 & -0.14 & -0.17 & 0.18 \\
\hline
\end{tabular}
$* \mathrm{P}<0.01$

${ }^{\mathrm{a}} \mathrm{AB}+$ : percentage of spermatozoa showing chromatin decondensation; DFI: percentage of spermatozoa with DNA fragmentation index values higher than $25 \%$; pY: percentage of tyrosine phosphorylated spermatozoa; TM: percentage of total motility; PM: percentage of live spermatozoa with progressive motility; VCL: curvilinear velocity; LIN: linearity coefficient; ALH: amplitude of lateral head displacement; Mitochondrial activity: percentage of live spermatozoa with active mitochondria; ROS: mean fluorescence intensity (MFI) of reactive oxygen species produced by live spermatozoa; Apoptotic sperm: percentage of spermatozoa showing apoptosis.

832 bHDS: percentage of spermatozoa with high DNA stainability.

833

834

835

836 
843 Table 3. Correlation coefficients between global DNA methylation and several variables in 844 fresh and cryopreserved spermatozoa incubated under capacitating (CAP) and non-capacitating 845 (NC) conditions. Correlations were estimated considering all incubation times under CAP or 846 NC conditions.

\begin{tabular}{|c|c|c|c|c|}
\hline \multirow{3}{*}{ Variables $^{\mathrm{a}}$} & \multicolumn{4}{|c|}{ DNA methylation $(\%)^{\mathrm{b}}$} \\
\hline & \multicolumn{2}{|c|}{ Fresh sperm } & \multicolumn{2}{|c|}{ Cryopreserved sperm } \\
\hline & CAP & $\mathrm{NC}$ & CAP & $\mathrm{NC}$ \\
\hline $\mathrm{AB}+(\%)$ & 0.04 & 0.06 & -0.18 & -0.47 \\
\hline $\operatorname{HDS}(\%)$ & 0.08 & 0.07 & -0.26 & -0.46 \\
\hline DFI $(\%)$ & 0.09 & -0.31 & 0.20 & 0.18 \\
\hline $\mathrm{pY}(\%)$ & 0.01 & 0.23 & -0.23 & -0.04 \\
\hline TM (\%) & 0.22 & 0.57 & -0.62 & -0.54 \\
\hline PM (\%) & -0.31 & 0.06 & -0.06 & -0.05 \\
\hline $\operatorname{VCL}\left(\mu \mathrm{m} \mathrm{s}^{-1}\right)$ & 0.01 & 0.03 & 0.05 & -0.04 \\
\hline LIN (\%) & -0.04 & 0.06 & 0.03 & 0.07 \\
\hline $\mathrm{ALH}(\mu \mathrm{m})$ & 0.05 & 0.09 & 0.12 & -0.21 \\
\hline Mitochondrial activity (\%) & -0.13 & -0.29 & -0.09 & -0.23 \\
\hline ROS (MFI) & 0.19 & -0.55 & 0.39 & 0.27 \\
\hline Apoptotic sperm (\%) & 0.28 & 0.14 & $0.61 *$ & 0.21 \\
\hline
\end{tabular}

$847 * \mathrm{P}<0.01$

848 a $\mathrm{AB}+$ : percentage of spermatozoa showing chromatin decondensation; HDS: percentage of 849 spermatozoa with high DNA stainability; DFI: percentage of spermatozoa with DNA 850 fragmentation index values higher than 25\%; pY: percentage of tyrosine phosphorylated 851 spermatozoa; TM: percentage of total motility; PM: percentage of live spermatozoa with 852 progressive motility; VCL: curvilinear velocity; LIN: linearity coefficient; ALH: amplitude of 853 lateral head displacement; Mitochondrial activity: percentage of live spermatozoa with active 854 mitochondria; ROS: mean fluorescence intensity (MFI) of reactive oxygen species produced by 855 live spermatozoa; Apoptotic sperm: percentage of spermatozoa showing apoptosis.

856 b DNA methylation: percentage of spermatozoa showing detectable levels of DNA methylation. 857 
1 Figure 2.

2 3

4

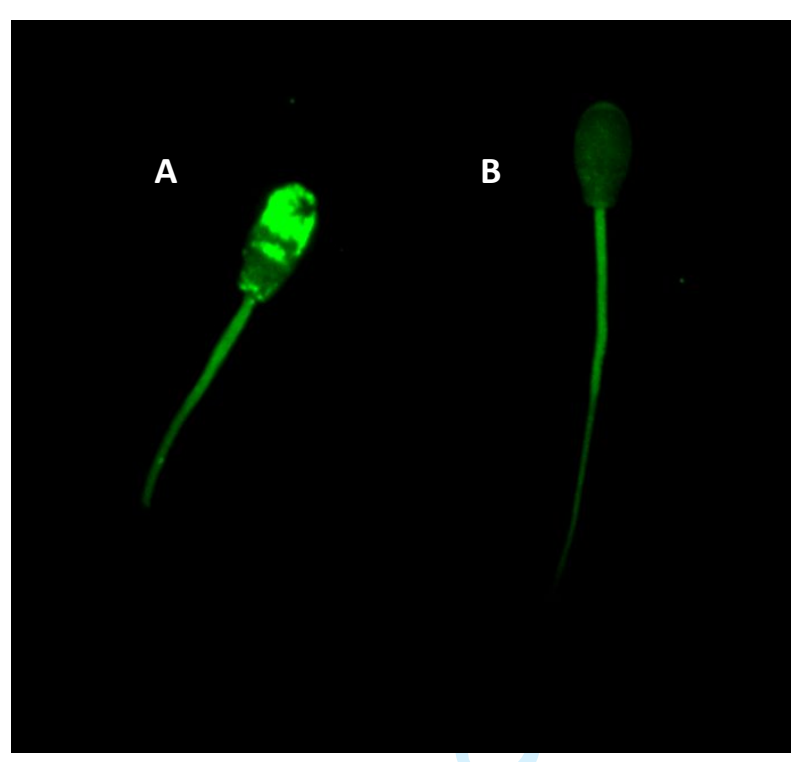

25

26

27

28

29

30

31

32

33

34

35

36

37

38

39

40

41

42

43

44

45

46

47

48

49

50

51

52

53

54

59

60 
$1 \quad$ Figure 3.
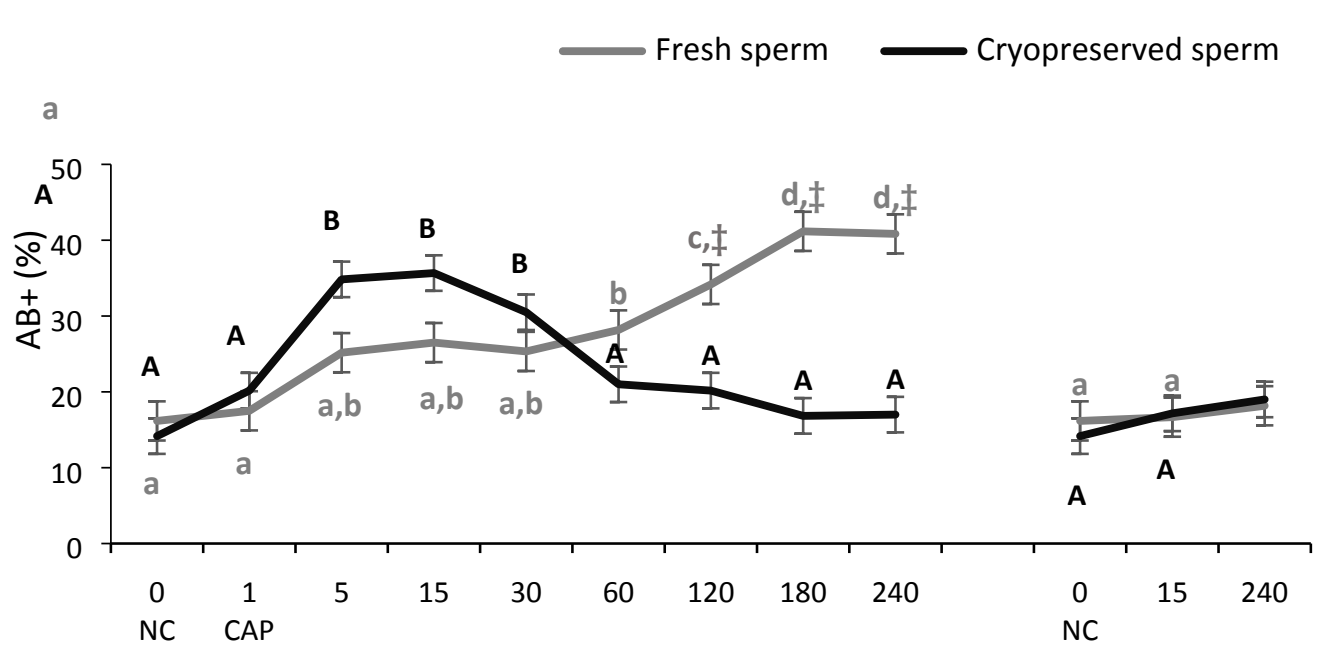

Incubation time (Min) 
$1 \quad$ Figure 4.

Fresh sperm $\longrightarrow$ Cryopreserved sperm

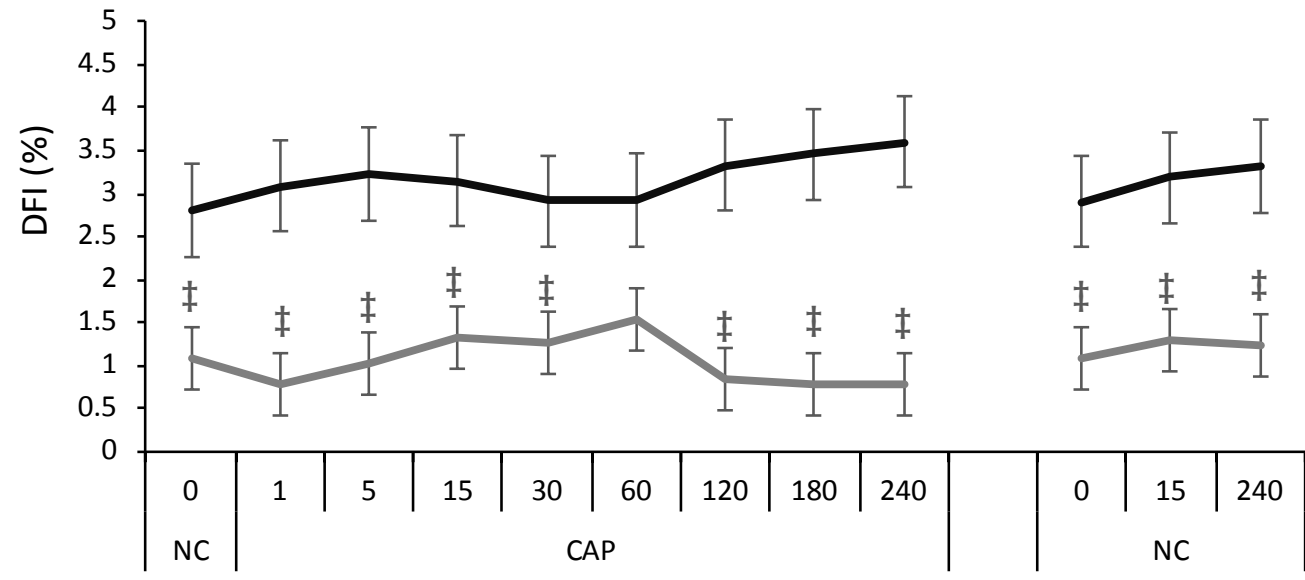

Incubation time (Min)

- Fresh sperm —Cryopreserved sperm

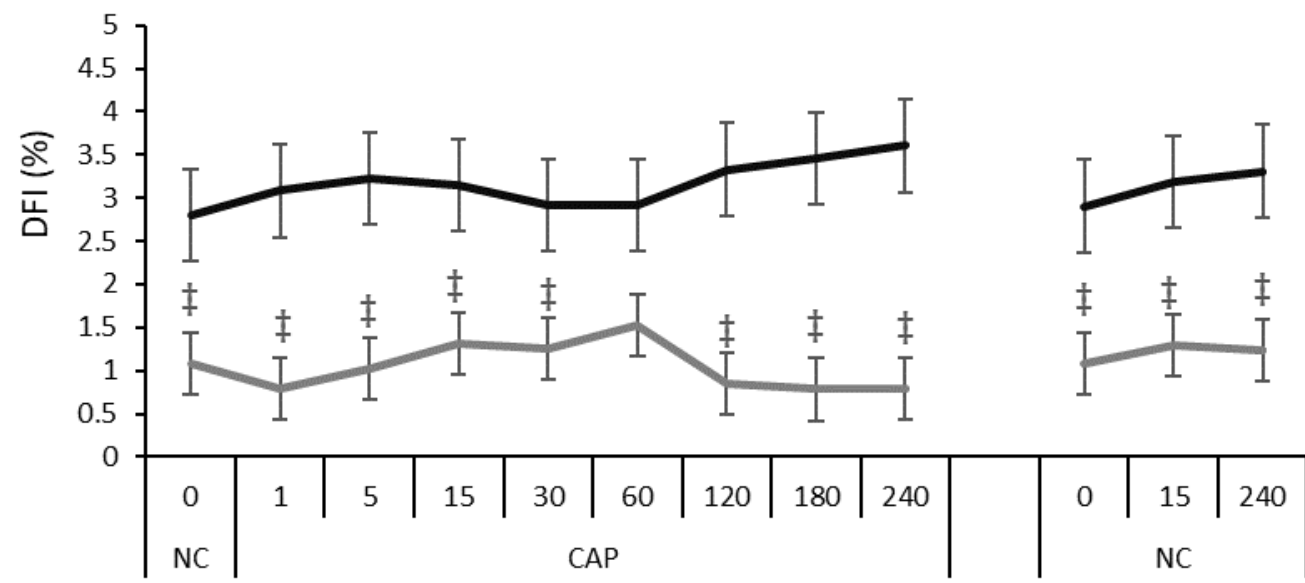

3

Incubation time (Min)
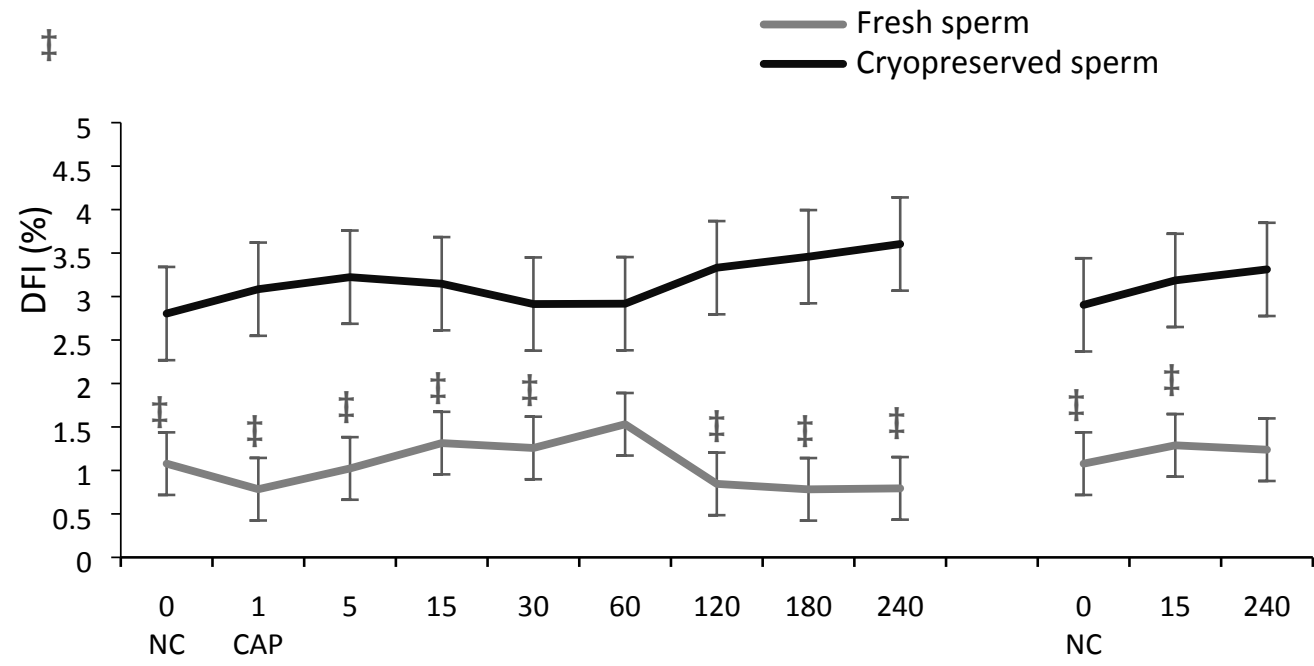

Incubation time (Min) 
$1 \quad$ Figure 5.

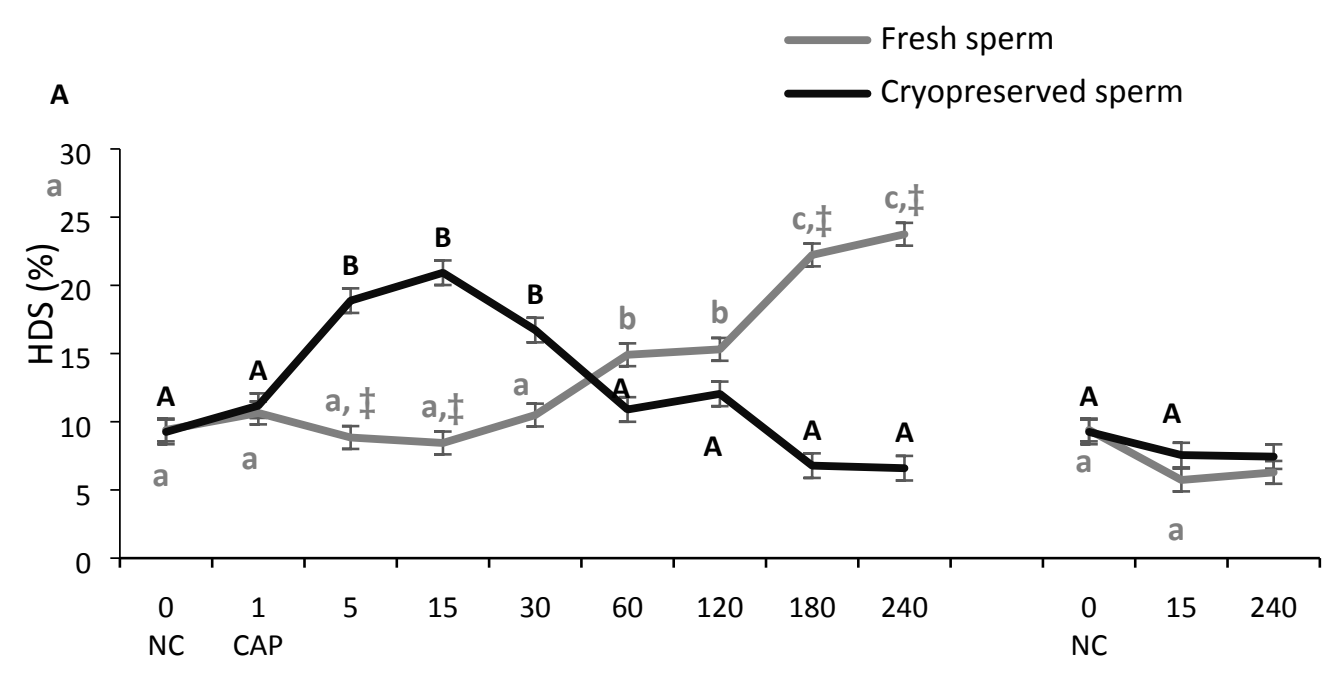

Incubation time (Min) 
$1 \quad$ Figure 6.

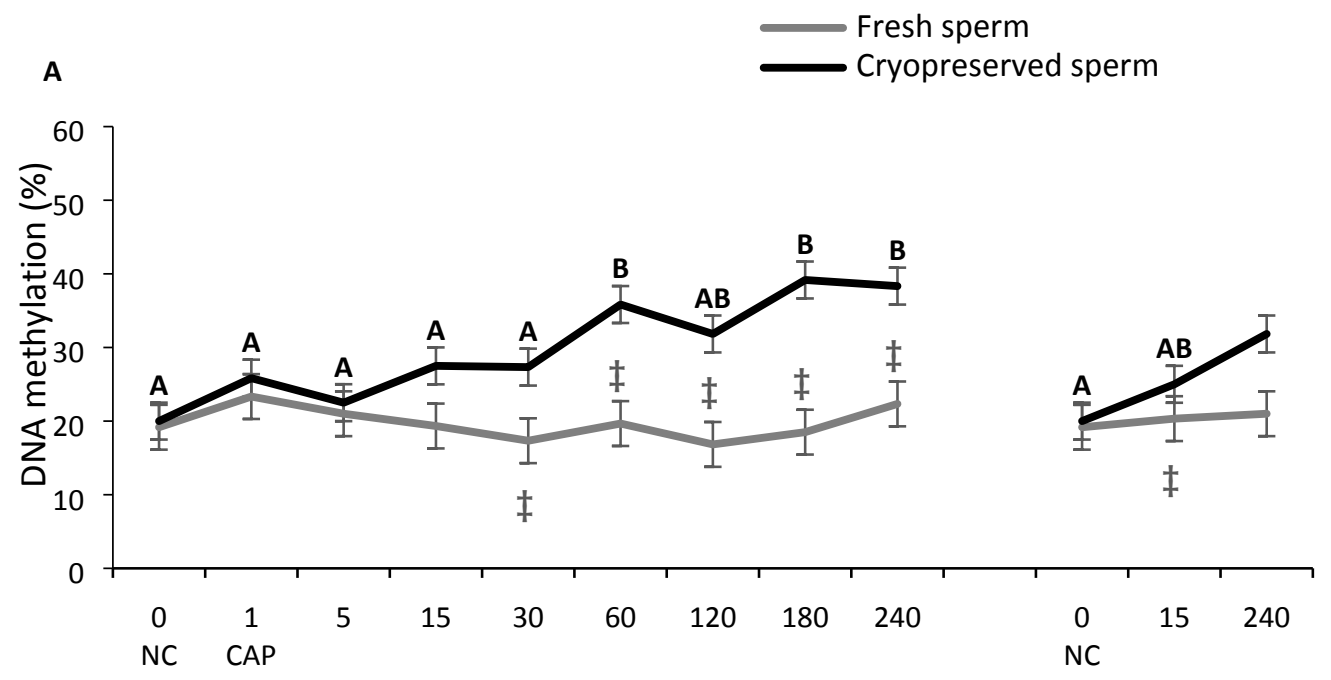

2

Incubation time (Min) 


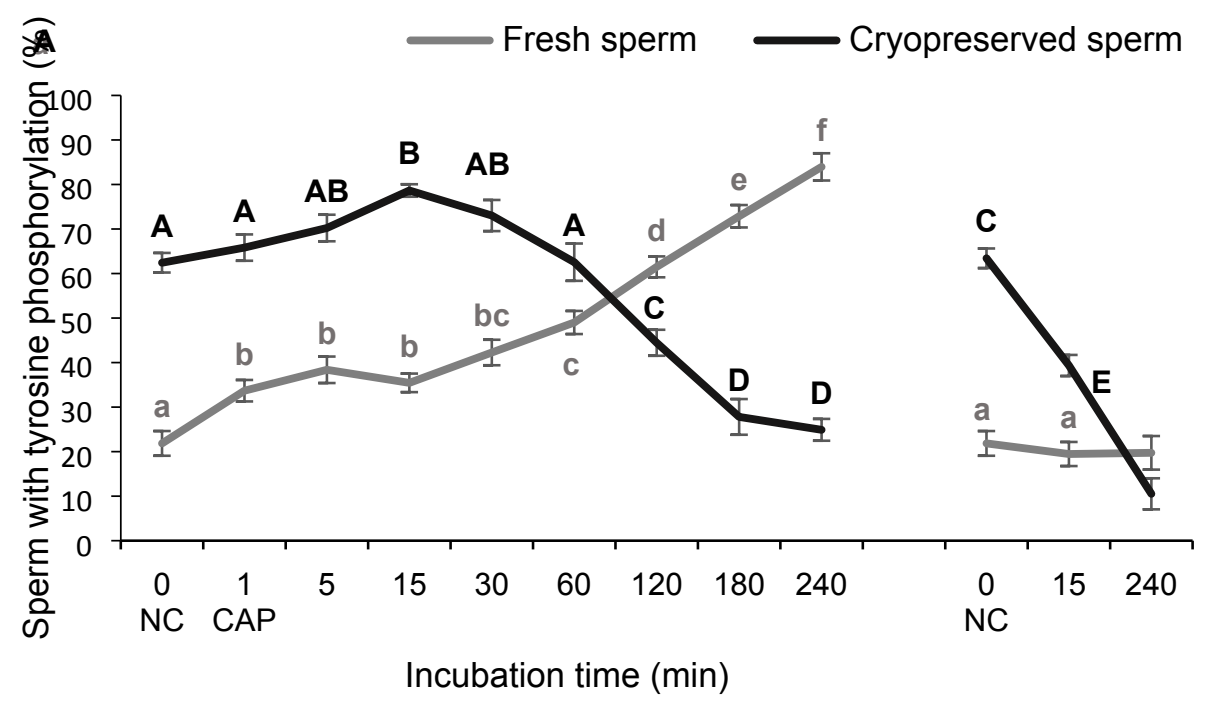

1

2 Supplementary Figure 1. Changes in the proportion of fresh and cryopreserved ram 3 spermatozoa showing tyrosine phosphorylation during the incubation period under 4 capacitating (CAP) and non-capacitating (NC) conditions. The mean percentage of 5 spermatozoa showing protein tyrosine phosphorylation \pm SEM at each time was 6 represented in the figure. Different letters illustrate significant differences $(\mathrm{P}<0.05)$ 7 among incubation times. Uppercase letters were used for cryopreserved spermatozoa and 8 lowercase letters for fresh spermatozoa. 
1 Supplementary table 1. Kinematic changes in fresh and cryopreserved ram spermatozoa incubated under CAP and NC conditions from 0 min to 240 min.

2 Values are expressed as means \pm SEM.

\begin{tabular}{|c|c|c|c|c|c|c|c|c|c|c|}
\hline \multirow{2}{*}{ Treatments } & \multicolumn{5}{|c|}{ Fresh sperm } & \multicolumn{5}{|c|}{ Cryopreserved sperm } \\
\hline & $\mathrm{TM}(\%)$ & PM (\%) & $\operatorname{VCL}\left(\mu \mathrm{m} \mathrm{s}^{-1}\right)$ & $\operatorname{LIN}(\%)$ & $\mathrm{ALH}(\mu \mathrm{m})$ & $\mathrm{TM}(\%)$ & PM (\%) & $\operatorname{VCL}\left(\mu \mathrm{m} \mathrm{s}^{-1}\right)$ & $\operatorname{LIN}(\%)$ & $\mathrm{ALH}(\mu \mathrm{m})$ \\
\hline $0 \mathrm{NC}$ & $54.96 \pm 0.58^{\mathrm{ab}}$ & $44.74 \pm 5.33^{\mathrm{ab}}$ & $32.33 \pm 0.48^{\mathrm{a}}$ & $86.50 \pm 1.56^{\mathrm{a}}$ & $1.35 \pm 0.07^{\mathrm{a}}$ & $36.77 \pm 3.68^{\mathrm{ab}}$ & $26.09 \pm 3.13^{\mathrm{a}}$ & $35.60 \pm 4.00^{\mathrm{a}}$ & $87.35 \pm 1.87^{\mathrm{a}}$ & $1.36 \pm 0.23^{\mathrm{a}}$ \\
\hline $1 \mathrm{CAP}$ & $53.15 \pm 3.00^{\mathrm{ab}}$ & $41.45 \pm 1.23^{\mathrm{ac}}$ & $45.89 \pm 2.93^{\mathrm{a}}$ & $72.18 \pm 1.94^{\mathrm{b}}$ & $1.76 \pm 0.18^{\mathrm{a}}$ & $34.28 \pm 3.50^{\mathrm{ab}}$ & $25.24 \pm 3.70^{\mathrm{a}}$ & $67.07 \pm 3.36^{\mathrm{b}}$ & $45.31 \pm 2.16^{b c}$ & $1.71 \pm 0.28^{\mathrm{a}}$ \\
\hline $5 \mathrm{CAP}$ & $51.98 \pm 2.47^{\mathrm{ab}}$ & $45.48 \pm 1.40^{\mathrm{ab}}$ & $47.84 \pm 0.84^{\mathrm{a}}$ & $62.98 \pm 2.15^{\mathrm{c}}$ & $1.62 \pm 0.39^{\mathrm{a}}$ & $33.22 \pm 4.23^{\mathrm{ab}}$ & $31.29 \pm 1.71^{\mathrm{ab}}$ & $115.17 \pm 10.39^{c}$ & $37.70 \pm 1.51^{\mathrm{d}}$ & $3.05 \pm 0.08^{\mathrm{b}}$ \\
\hline $15 \mathrm{CAP}$ & $57.06 \pm 1.14^{\mathrm{a}}$ & $36.80 \pm 2.25^{\mathrm{ac}}$ & $87.18 \pm 3.05^{\mathrm{bc}}$ & $64.91 \pm 1.06^{\mathrm{c}}$ & $1.55 \pm 0.24^{\mathrm{a}}$ & $42.79 \pm 2.00^{\mathrm{a}}$ & $36.41 \pm 2.43^{\mathrm{b}}$ & $160.54 \pm 7.68^{\mathrm{d}}$ & $35.83 \pm 1.56^{\mathrm{d}}$ & $4.17 \pm 0.19^{c}$ \\
\hline $15 \mathrm{NC}$ & $25.05 \pm 1.83^{\mathrm{c}}$ & $18.69 \pm 4.59^{\mathrm{d}}$ & $40.76 \pm 6.54^{\mathrm{a}}$ & $66.47 \pm 0.23^{b c}$ & $1.41 \pm 0.25^{\mathrm{a}}$ & $12.76 \pm 2.52^{\mathrm{cd}}$ & $11.35 \pm 1.14^{\mathrm{cd}}$ & $33.29 \pm 1.17^{\mathrm{a}}$ & $58.86 \pm 1.74^{\mathrm{e}}$ & $1.08 \pm 0.26^{\mathrm{a}}$ \\
\hline $30 \mathrm{CAP}$ & $46.64 \pm 4.05^{\mathrm{b}}$ & $44.92 \pm 0.76^{\mathrm{ac}}$ & $83.85 \pm 4.00^{\mathrm{b}}$ & $66.44 \pm 2.65^{\mathrm{bc}}$ & $1.89 \pm 0.55^{\mathrm{a}}$ & $30.73 \pm 1.26^{\text {be }}$ & $22.22 \pm 6.10^{\mathrm{a}}$ & $131.17 \pm 0.15^{\mathrm{c}}$ & $41.13 \pm 1.95^{\mathrm{dc}}$ & $3.61 \pm 0.29^{\mathrm{bc}}$ \\
\hline $60 \mathrm{CAP}$ & $46.05 \pm 1.06^{\mathrm{b}}$ & $42.53 \pm 5.66^{\mathrm{dc}}$ & $104.52 \pm 9.72^{\mathrm{cd}}$ & $51.31 \pm 2.55^{\mathrm{d}}$ & $1.77 \pm 0.35^{\mathrm{a}}$ & $19.59 \pm 4.32^{\mathrm{ce}}$ & $12.50 \pm 1.79^{c}$ & $75.66 \pm 4.00^{\mathrm{b}}$ & $49.28 \pm 2.58^{b}$ & $1.95 \pm 0.55^{\mathrm{a}}$ \\
\hline 120 CAP & $46.11 \pm 2.26^{\mathrm{b}}$ & $41.60 \pm 4.02^{\mathrm{ac}}$ & $119.23 \pm 4.97^{\mathrm{d}}$ & $45.69 \pm 2.39^{d}$ & $3.08 \pm 0.33^{\mathrm{b}}$ & $12.72 \pm 1.88^{\mathrm{cd}}$ & $5.83 \pm 1.30^{\text {ce }}$ & $41.95 \pm 2.29^{\mathrm{a}}$ & $49.92 \pm 0.67^{\mathrm{b}}$ & $1.51 \pm 0.24^{\mathrm{a}}$ \\
\hline $180 \mathrm{CAP}$ & $58.24 \pm 1.84^{\mathrm{a}}$ & $37.28 \pm 1.13^{\mathrm{a}}$ & $157.69 \pm 1.99^{\mathrm{e}}$ & $37.88 \pm 2.06^{\mathrm{e}}$ & $3.58 \pm 0.43^{\mathrm{c}}$ & $3.66 \pm 2.20^{\mathrm{d}}$ & $2.84 \pm 1.13^{\mathrm{de}}$ & $42.18 \pm 1.55^{\mathrm{a}}$ & $48.15 \pm 3.31^{\mathrm{bc}}$ & $1.58 \pm 0.11^{\mathrm{a}}$ \\
\hline 240 CAP & $58.87 \pm 1.57^{\mathrm{a}}$ & $29.58 \pm 3.95^{b}$ & $165.27 \pm 4.34^{\mathrm{e}}$ & $38.40 \pm 1.17^{\mathrm{e}}$ & $4.33 \pm 0.33^{\mathrm{c}}$ & $4.01 \pm 0.95^{\mathrm{d}}$ & $3.33 \pm 1.38^{\mathrm{ce}}$ & $34.50 \pm 2.03^{\mathrm{a}}$ & $45.68 \pm 0.29^{\mathrm{bc}}$ & $1.18 \pm 0.44^{\mathrm{a}}$ \\
\hline $240 \mathrm{NC}$ & $15.66 \pm 2.41^{\mathrm{d}}$ & $5.65 \pm 1.44^{\mathrm{e}}$ & $31.97 \pm 1.90^{\mathrm{a}}$ & $61.95 \pm 1.51^{\mathrm{c}}$ & $0.79 \pm 0.12^{\mathrm{a}}$ & $4.31 \pm 2.67^{\mathrm{d}}$ & $0.60 \pm 0.12^{\mathrm{e}}$ & $22.03 \pm 4.74^{\mathrm{a}}$ & $48.90 \pm 0.59^{b}$ & $0.75 \pm 0.08^{\mathrm{a}}$ \\
\hline
\end{tabular}

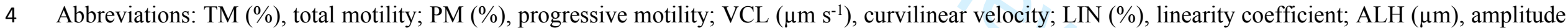

5 of lateral head displacement.

6 Different letters indicate significant differences $(\mathrm{P}<0.05)$ among incubation times for each parameter. 
11 Supplementary table 2. Changes in viability, apoptosis, mitochondrial activity and ROS production in fresh and cryopreserved ram spermatozoa incubated under $\mathrm{CAP}$ and $\mathrm{NC}$ conditions from $0 \mathrm{~min}$ to $240 \mathrm{~min}$. Values are expressed as means $\pm \mathrm{SEM}$.

\begin{tabular}{|c|c|c|c|c|c|c|c|c|}
\hline \multirow[b]{2}{*}{ Treatments } & \multicolumn{4}{|c|}{ Fresh sperm } & \multicolumn{4}{|c|}{ Cryopreserved sperm } \\
\hline & Viability (\%) & Apoptosis (\%) & $\begin{array}{c}\text { Mitochondrial } \\
\text { activity }(\%)\end{array}$ & ROS (MFI) & Viability (\%) & Apoptosis (\%) & $\begin{array}{c}\text { Mitochondrial } \\
\text { activity }(\%)\end{array}$ & ROS (MFI) \\
\hline $0 \mathrm{NC}$ & $54.88 \pm 4.62^{\mathrm{a}}$ & $19.41 \pm 3.60$ & $36.15 \pm 3.88^{\mathrm{a}}$ & $68.10 \pm 1.80^{\mathrm{a}}$ & $39.25 \pm 1.34^{\mathrm{a}}$ & $13.18 \pm 2.21^{\mathrm{a}}$ & $24.15 \pm 0.16^{\mathrm{ab}}$ & $100.53 \pm 4.93^{\mathrm{a}}$ \\
\hline $1 \mathrm{CAP}$ & $50.13 \pm 6.57^{\mathrm{ab}}$ & $20.26 \pm 5.62$ & $39.77 \pm 4.89^{\mathrm{ab}}$ & $39.33 \pm 1.47^{b}$ & $34.90 \pm 2.18^{\mathrm{a}}$ & $16.91 \pm 1.44^{\mathrm{ab}}$ & $28.16 \pm 4.25^{\mathrm{ab}}$ & $66.47 \pm 1.76^{\mathrm{b}}$ \\
\hline $5 \mathrm{CAP}$ & $50.51 \pm 7.35^{\mathrm{ab}}$ & $18.77 \pm 4.52$ & $40.09 \pm 5.39^{\mathrm{ab}}$ & $42.13 \pm 4.22^{b}$ & $31.54 \pm 3.56^{\mathrm{a}}$ & $17.24 \pm 0.44^{\mathrm{ab}}$ & $32.11 \pm 0.52^{\mathrm{ac}}$ & $63.50 \pm 3.05^{\mathrm{b}}$ \\
\hline $15 \mathrm{CAP}$ & $46.99 \pm 5.65^{\mathrm{ac}}$ & $17.84 \pm 4.43$ & $40.28 \pm 5.72^{\mathrm{ab}}$ & $37.43 \pm 1.73^{b}$ & $38.18 \pm 2.98^{\mathrm{a}}$ & $14.09 \pm 2.40^{\mathrm{ab}}$ & $38.34 \pm 4.34^{c}$ & $68.10 \pm 8.18^{\mathrm{b}}$ \\
\hline $15 \mathrm{NC}$ & $25.95 \pm 4.42^{\mathrm{c}}$ & $19.83 \pm 4.23$ & $25.00 \pm 3.20^{\mathrm{c}}$ & $75.53 \pm 1.50^{\mathrm{ac}}$ & $15.78 \pm 1.95^{\mathrm{b}}$ & $19.96 \pm 4.01^{\mathrm{bc}}$ & $13.02 \pm 0.39^{\mathrm{d}}$ & $97.33 \pm 5.19^{\mathrm{a}}$ \\
\hline $30 \mathrm{CAP}$ & $40.68 \pm 1.59^{\mathrm{bc}}$ & $15.26 \pm 1.47$ & $28.31 \pm 3.39^{c}$ & $40.80 \pm 2.22^{\mathrm{b}}$ & $32.24 \pm 2.66^{\mathrm{a}}$ & $16.07 \pm 1.50^{\mathrm{ab}}$ & $35.32 \pm 4.56^{\mathrm{c}}$ & $59.03 \pm 6.98^{b}$ \\
\hline $60 \mathrm{CAP}$ & $40.45 \pm 8.38^{c}$ & $14.53 \pm 2.66$ & $23.47 \pm 8.01^{\mathrm{c}}$ & $49.93 \pm 2.07^{\mathrm{b}}$ & $20.32 \pm 5.96^{\mathrm{ab}}$ & $24.71 \pm 1.81^{\mathrm{c}}$ & $17.53 \pm 4.70^{\mathrm{b}}$ & $52.33 \pm 1.16^{\mathrm{b}}$ \\
\hline $120 \mathrm{CAP}$ & $36.99 \pm 2.76^{c}$ & $15.36 \pm 0.25$ & $30.72 \pm 7.50^{c}$ & $49.33 \pm 7.90^{\mathrm{b}}$ & $13.07 \pm 2.16^{\mathrm{b}}$ & $28.77 \pm 0.79^{c}$ & $9.95 \pm 1.28^{\mathrm{d}}$ & $67.17 \pm 1.92^{\mathrm{b}}$ \\
\hline $180 \mathrm{CAP}$ & $44.05 \pm 2.18^{\mathrm{ac}}$ & $15.59 \pm 1.90$ & $45.39 \pm 1.90^{\mathrm{b}}$ & $42.23 \pm 1.94^{\mathrm{b}}$ & $4.94 \pm 1.45^{\mathrm{c}}$ & $32.99 \pm 0.59^{\mathrm{d}}$ & $8.68 \pm 1.31^{\mathrm{d}}$ & $73.33 \pm 1.69^{\mathrm{c}}$ \\
\hline $240 \mathrm{CAP}$ & $44.13 \pm 3.72^{\mathrm{ac}}$ & $19.04 \pm 7.40$ & $45.87 \pm 2.30^{\mathrm{b}}$ & $50.80 \pm 1.34^{\mathrm{b}}$ & $3.51 \pm 0.13^{c}$ & $32.88 \pm 0.42^{\mathrm{d}}$ & $7.03 \pm 1.25^{\mathrm{de}}$ & $84.60 \pm 2.97^{\mathrm{c}}$ \\
\hline $240 \mathrm{NC}$ & $13.26 \pm 1.52^{\mathrm{d}}$ & $20.75 \pm 6.34$ & $14.08 \pm 1.81^{\mathrm{d}}$ & $83.97 \pm 1.76^{c}$ & $4.08 \pm 0.83^{c}$ & $16.51 \pm 0.69^{\mathrm{a}}$ & $2.82 \pm 1.29^{\mathrm{e}}$ & $116.80 \pm 4.33^{\mathrm{d}}$ \\
\hline
\end{tabular}

Abbreviations: Viability (\%), percentage of live spermatozoa; Apoptosis (\%), percentage of apoptotic spermatozoa; Mitochondrial activity (\%), percentage of

live spermatozoa with active mitochondria; ROS (MFI), mean fluorescence intensity (MFI) of reactive oxygen species (ROS) produced by live spermatozoa.

Different letters indicate significant differences $(\mathrm{P}<0.05)$ among incubation times for each parameter. 